\title{
TRITIUM GENERATION FROM THE INTERACTION OF A GLOW DISCHARGE PLASMA WITH METALS AND WITH A MAGNETIC FIELD
}

\author{
V.A. ROMODANOV \\ FSUE SRI SPA "LUTCH" \\ Zheleznodorozhnaya 24, Podolsk, Moscow reg. 142100. Russia. Tel.: 095-137-9258. Fax: \\ 095-137-9384 \\ E-mail: luchatis.dhtp.kiae.ru/istokistok.sialuch.ru
}

\begin{abstract}
We present results of our research on tritium generation through the bombardment of the surface of various metals by accelerated ions of hydrogen isotopes from a glow discharge plasma, with and without a magnetic field. The introduction of a magnetic field perpendicular to the sample surface results in an increase in the tritium activity, and in the tritium generation rate, of almost two orders of magnitude as compared to similar experiments run with no magnetic field. The largest tritium generation rates observed were obtained with the glow discharge operating in a magnetic field, and were in the range $10^{9}-10^{10} \mathrm{atom} / \mathrm{s}$. This is higher than our background by three to four orders of magnitude. The use of a magnetic field has resulted in good reproducibility, and the development of a reliable tritium generation rate of about $10^{10}$ atom/s for tantalum, tungsten, and platinum.
\end{abstract}

A new technique for the generation and measurement of excess heat is presented based on the transfusion of hydrogen isotopes through the metal wall of a hollow sample electrode toward the glow discharge. In the case of a vanadium cathode, the maximum excess thermal power is about $30 \%$ of the absorbed power. The generation of excess power is found to be maximized in the temperature $600-700 \mathrm{~K}$ for relative power, and $800-1000 \mathrm{~K}$ for absolute power. The results of measurements support a nuclear origin for the tritium generation, as opposed to a conventional thermal activation explanation.

Mass spectroscopic measurements show an increase in species with deuterium in discharge experiments with hydrogen gas and with deuterium gas. The tritium generation rate is found to increase with the addition of deuterium, but by an amount not commensurate with the amount of deuterium added. Measurements of the gamma spectrum indicate that positrons are not generated in the course of tritium generation. These observations allow us to assert that modified versions of $\mathrm{p}+\mathrm{p}$ and $\mathrm{p}+\mathrm{d}$ reactions are responsible for the production of deuterium and tritium; where the reactions in these experiments proceed through electronic catalysis, as $\mathrm{p}+\mathrm{e}+\mathrm{p}$ and $\mathrm{p}+\mathrm{e}+\mathrm{d}$. The production of excess heat at the level of $1 \mathrm{~kW}$ through this reaction mechansim (and under these discharge conditions with hydrogen isotopes) would be associated with a tritium generation rate of about $10^{12} \mathrm{atom} / \mathrm{s}$. 


\section{Introduction}

We have reported previously ${ }^{1-3}$ that the interaction of accelerated ions of hydrogen isotopes from a low-energy $(<10 \mathrm{keV})$ glow discharge plasma with metals can result in intense tritium generation (up to $10^{9} \mathrm{atom} / \mathrm{s}$, using deuterium gas of technical cleanliness composed of $95 \% \mathrm{D}_{2}+5 \% \mathrm{H}_{2}$, volumetric). It was also found that the use of a natural mix of a hydrogen isotopes $\left(0.015 \% \mathrm{D}_{2}+\mathrm{H}_{2} 99.985 \%\right)$, can result in high rates of tritium production, and a tritium generation rate of $10^{8}$ atom $/ \mathrm{s}$ was measured. ${ }^{4}$ The reproducibility in the case of similar experiments has not been sufficient for normal scientific research and unequivocal conclusions, as measured values of the tritium generation rate could differ from experiment to experiment by three orders of magnitude due to minor differences in experimental conditions.

Further studies have shown that the poor reproducibility is connected to the problem of uncontrollable tritium absorption by some constructional elements of the working chamber, that could lead to an unpredictable appearance of tritium resulting in a degradation of the experimental results. ${ }^{5,6}$ We have now managed to achieve good reproducibility. This is due to a combination of improvements in technique that include: the removal of most "tritium-active" constructional elements of structure of the working chamber, improvements in the technique of gas removal from internal surfaces of the working chamber and samples, and purges of the working liquid for the roughing-down pump by ballast gas after each experiment. ${ }^{7}$ The reliable reproducibility of experiments, with the absence of uncontrolled tritium emission from the installation and samples, has allowed us to return to areas of our basic research interests, which include: studying the interaction for hydrogen isotopes with metals in the glow discharge, and revisiting experiments with pulsed current and an external magnetic field, which earlier gave the highest tritium generation rate. ${ }^{8}$

The purpose of the present work was the study of tritium generation and excess heat, from the interaction of mixes of hydrogen isotopes with metal surfaces in a plasma glow discharge, and the effects due to an imposed magnetic field.

\section{Experimental Approach}

One focus of our research has been on the interaction of hydrogen isotopes with metals includes the acceleration of positive ions in the glow discharge at constant current at elevated pressure, and the consequences that occur when these ions are incident on the surface of different metals. ${ }^{1,2,8}$ We briefly describe in this section the experimental approach we used.

\subsection{The discharge facility}

The research was carried out at the UVN-84R-1 facility, a schematic of which is illustrated in Fig. 1. In facility is described in detail in Ref. [9]. The facility includes a turbo-molecular pump (23) for evacuating the chamber (3), in which is placed a simple hollow cathode (4). The sample cavity is pumped out by a 


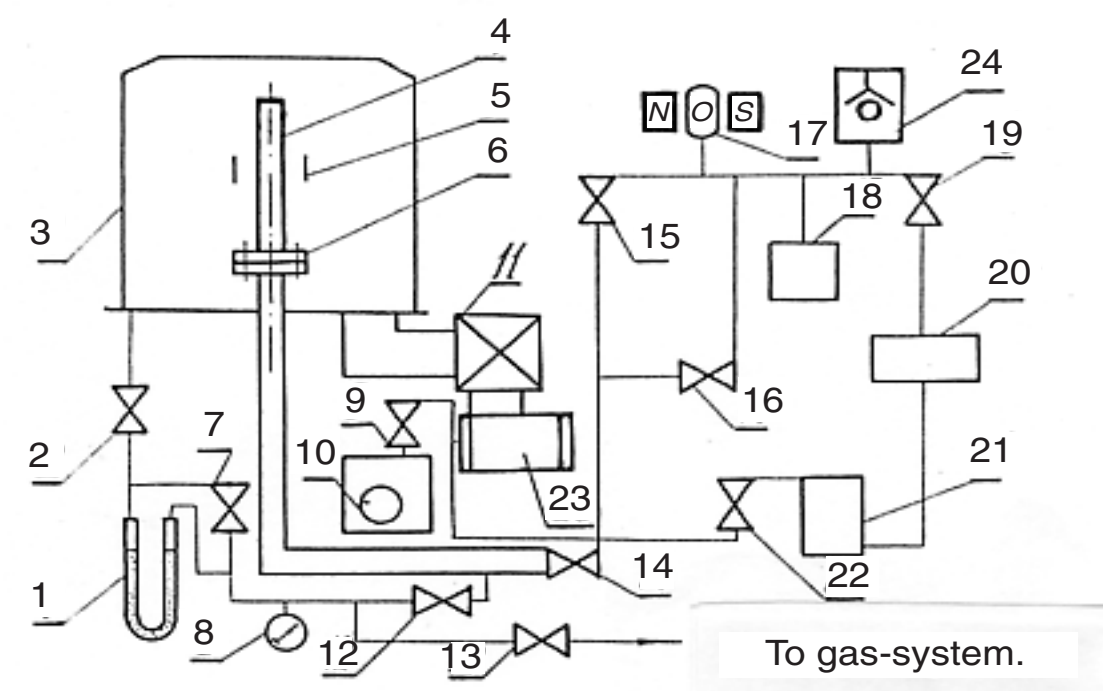

Figure 1. The scheme of installation on research of a hydrogen mass-spectrum. 1: Differential manometer; 2: 7.9.12.13.14.15.16.19.2; 2: valves; 3: chamber; 4: sample-cathod; 5: anode; 6: flange; 8: manometer; 10: roughing-down pump; 11: high-vaccum valve; 17: IPDO-2; 18: NORD250; 20: TMP-200; 21: nitric trap; 23: TMP-500; 24: mass-spectrometer MX-7304.

different turbo-molecular pump (20), and the electrodischarge (18) with a control for the pumped-out gases of mass-spectrometers MX-7304 and IPDO-2. The sample consists of a hollow cylinder, sealed on one side and welded to a fastening flange on the other. The sample thickness in the case of vanadium, molybdenum, niobium, and titanium is $0.5-4 \mathrm{~mm}$, the outside diameter is $10-20 \mathrm{~mm}$, and the length is $20-100 \mathrm{~mm}$.

The pressure of the (plasma-forming) gas is maintained in the range 0.5$25 \times 10^{3} \mathrm{~Pa}$. The sample temperature varied in the range $300-1800 \mathrm{~K}$ due to the power supplied by the glow discharge, which was run at voltages in the range 200$700 \mathrm{~V}$ and current densities in the range $50-1000 \mathrm{~A} / \mathrm{m}^{2}$. The temperature is measured using thermocouples (TR5/TR20) placed outside of the operative range of the discharge, and using optical pyrometers (OMP-54), with an error is not higher than $\pm 10 \%$. The sensitivity of the measurement system on the hydrogen flow was no worse than $10^{9}$ atom/s. An (arch-type) magnetic field was implemented perpendicular to the plane of the cathode as illustrated in Fig. 2 using water-cooled magnetrons.

The device consists of a water-cooled vacuum chamber (1), in which the magnetron system (4) with water cooling (5) and barium ferrite permanent magnet (6) is placed. The sample-cathode (3) is placed on the magnetron surface and could be cooled by it. Because of heterogeneity of the distribution of magnetic field lines (7) in space, the magnetic field on the sample surface was in the range 0.002-0.02 T. The magnetic field distribution was kept constant during the experiment by using water cooling. The ring anode (2), placed coaxial with the sample at a distance of 


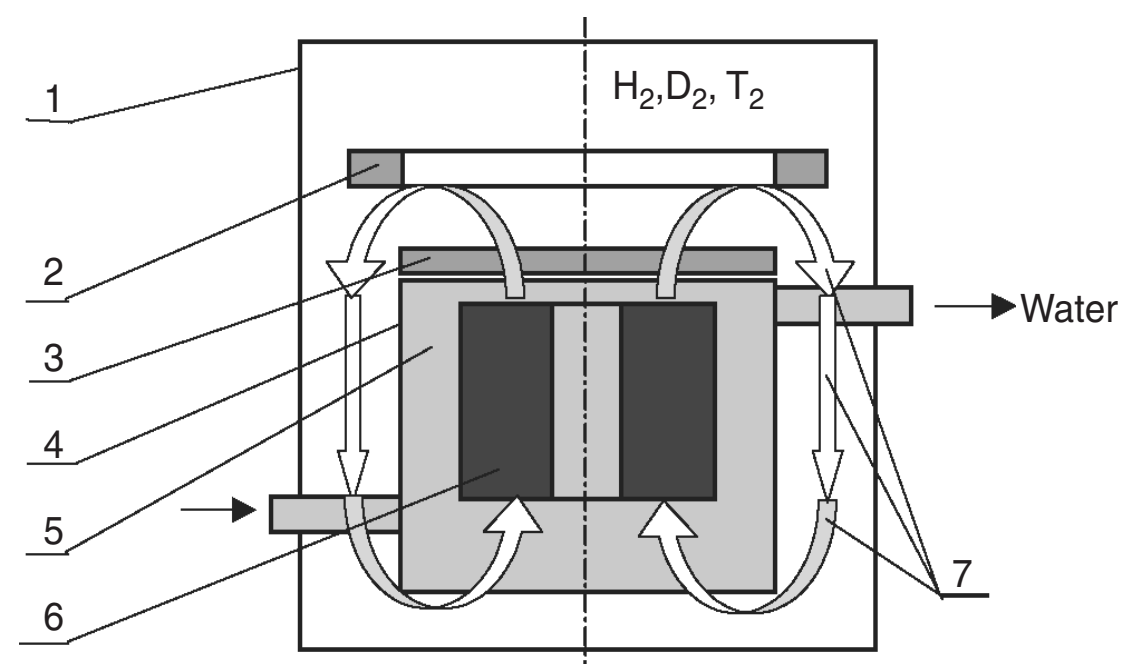

Figure 2. The scheme of the device on research of interaction of hydrogen isotopes with metals in the glow discharge at imposing a magnetic field. 1: Vacuum chamber; 2: anode; 3: sample-cathode; 4: tank of magnetrons; 5: cooling water; 6: permanent magnet; 7: magnetic field lines.

5-50 mm, was at high voltage. The sample temperature, and distance between the anode and cathode, could be adjusted. The chamber (1), after the removal of gases and pump out, could be filled with a mix of hydrogen isotopes containing of various ratios, or inert gases. In similar experiments we used flat samples of various metals, with a diameter of $100 \mathrm{~mm}$ and thickness of $0.1-2 \mathrm{~mm}$. Rings and cores of corrosionproof steel or molybdenum were used for the anode. We used titanium, niobium, molybdenum, tantalum, and tungsten samples of technical cleanliness, with impurity levels no more than $1 \%$ by mass. We used a mix of hydrogen isotopes with a concentration $1.5 \times 10^{-2} \%$ deuterium in ordinary hydrogen; or deuterium gas with a technical cleanliness of $95 \% \mathrm{D}_{2}+5 \% \mathrm{H}_{2}$ atomic shares; or a mix of hydrogen isotopes or helium- 4 with the an impurity content of no more than $1 \%$ by mass.

The power supply used a rectifier (that was not stabilised) with a ballast resistor, giving a maximal voltage up to $6 \mathrm{kV}$ and current up to $3 \mathrm{~A}$.

\subsection{Background measurements}

Background measurements were done using cylindrical hollow samples of molybdenum sealed on one end, and attached to water-cooled flanges on the other. ${ }^{4}$ These samples have a diameter of $23 \mathrm{~mm}$, a length of $100 \mathrm{~mm}$, and a wall thickness of $1 \mathrm{~mm}$. For such samples we carried out experiments as with thermal activation, with heating from a tungsten resistive heater, and with the glow discharge using a natural mix of hydrogen isotopes. In these experiments, it was possible to assess whether tritium leaked in from elements of the vacuum chamber and equipment. The thermal activation was not applied to flat samples because of powerful cooling of samples due to the water-cooled substrate. 


\subsection{Experimental protocol}

The experiments were carried out as follows: The sample is initially fixed on cooled magnetrons, then the chamber is pumped out, and then degassed with help of the resistive heater running at a power up to $10 \mathrm{~kW}$. After the removal of superfluous gases and the cooling of internal parts of the chamber to below $400 \mathrm{~K}$, the chamber is filled the desired mix of hydrogen isotopes to operating pressure. High voltage is applied to the anode, which initiates the glow discharge and establishes necessary current, voltage and temperature conditions at the sample. The discharge and experimental parameters are maintained for a certain time $(2-50 \mathrm{~h})$, then the plasma-forming gas is pumped from the chamber by the vacuum pump in into rubber "pillows" and the discharge is switched off.

Hydrogen from the "pillows" is mixed with air and burned on a heated spiral in a cylindrical furnace of a special installation. Water produced from the burning is frozen in a cooled trap at a temperature of $260-270 \mathrm{~K}$. Then $0.2 \mathrm{ml}$ of the formed water enters a $5 \mathrm{ml}$ liquid scintillator (ZS-8) and the tritium content is measured at the BETA-2 facility. The efficiency of measurement $\beta$-particles in these measurements was $28 \%$ using VNIIFTRI standards. The measurement error for tritium content in these tests did not exceed $\pm 50 \%$.

For background measurements on flat samples with substrate water-cooling and magnetic field we used inert helium for the gas discharge. A philosophy of measurement have kept the former use of the addition of the initial hydrogen in the pillow with helium completely pumped out from the working volume after termination of the experiment. For maximal catching of trace tritium the additional hydrogen also was pumped through working volume. Thus, we could compare the tritium generation rate for isotopes of hydrogen and helium under conditions with approximately the same influence of thermal and radiating effects. The third series of background measurements consists of the use of flat samples on a cooled substrate in the glow discharge using a gas of hydrogen isotopes, but without use of an external magnetic field. This series of measurements allowed us to determine the influence of the magnetic field on the tritium generation rate, with comparable thermo-desorption and electro-migration effects.

\subsection{Radiation detection}

Measurements of radiation intensity of a gammas with an energy near $510.8 \mathrm{keV}$ were made using a gamma spectrometer station. We used a high purity planar $5 \mathrm{~cm}^{2}$ germanium detector from Canberra with a portable (notebook) computer, and GENIE-2000 software. The choice of size amplification, as the power calibration has shown, provided for a measurement of the background gamma energies in a range of energy from 30 to $2000 \mathrm{keV}$. The background and possible gamma radiation at the working installation was measured over $7000 \mathrm{~s}$. The distance from the detector to the centre of discharge unit is about $120 \mathrm{~mm}$; from the detector to the outside wall of the chamber is about $20 \mathrm{~mm}$. Between the detector and the possible source of gamma radiation was a water-cooled wall of the facility, with a wall of thickness 


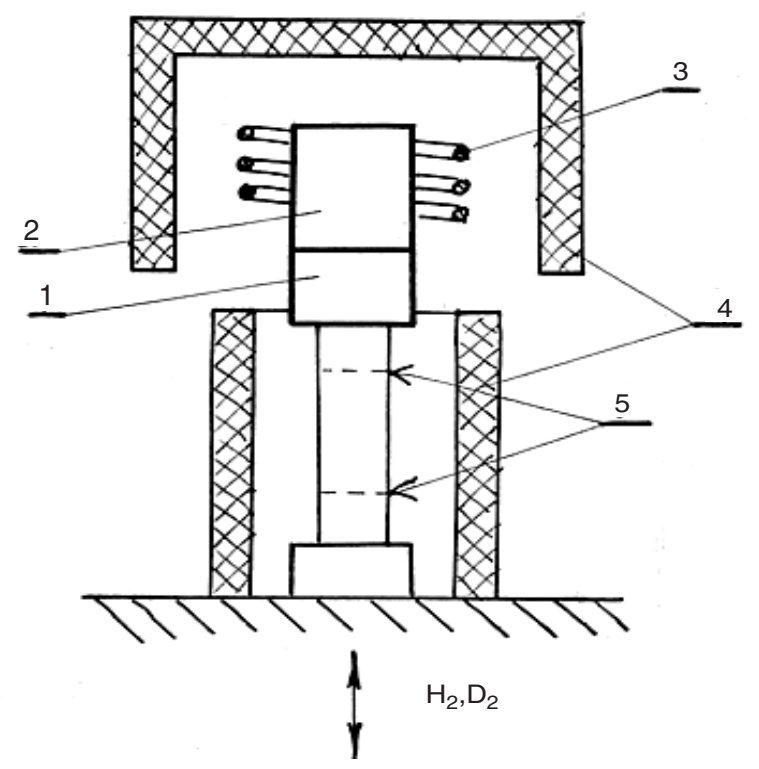

Figure 3. The scheme for definition of the thermal effects in the glow discharge. 1: Basis of a sample from molybdenum; 2: cup of the sample of hydride-forming metal; 3: anode; 4: ceramic isolators; 5: thermocouples.

$5 \mathrm{~mm}$ made of steel (12C18N10T). The measurement efficiency was determined using sources consisting of radioactive solutions of Cs-137 and Ba-133. At $511 \mathrm{keV}$ the detection efficiency was measured to be $0.00013 \pm 0.00003$.

\subsection{Thermal measurements}

The scheme used for measuring thermal effects associated with a cathode sample in a glow discharge experiment with hydrogen isotopes is shown in Fig. 3. The system consists of a molybdenum base (1), with a cup welded on it (2) made of a hydride-forming metal (such as niobium, vanadium or zirconium). Thermocouples (5) were welded at different distances from the sample into the molybdenum base as shown. The thermocouples (TR5/20) allowed us to determine the thermal flow from the sample to a water-cooled sink through a material (Mo) with a known thermal resistance. The sample was surrounded by the ring anode (3), and by ceramic cylinders (4) of quartz and zirconium oxides to reduce thermal losses.

The basic philosophy of the thermal measurement can be described as follows. In the beginning, the working chamber filled by hydrogen isotopes and a discharge is ignited between the electrodes, one of which is the sample. In the sample cavity a vacuum is created using a roughing pump and a turbomolecular pump. Then the sample temperature becomes elevated, and the glow discharge is operated under stable discharge parameters for $2-6 \mathrm{~h}$, leading to a constant heat flow that can be measured. The temperature difference between the thermocouples in the molybde- 
num basis is measured, and the heat flow is calculated from

$$
Q=-\lambda S\left(\frac{\mathrm{d} T}{\mathrm{~d} l}\right)
$$

where $\lambda$ is the thermal conduction coefficient of molybdenum in the relevant temperature range, where $S$ is the cross sectional area of the molybdenum basis, and where and $\frac{d T}{d l}$ is the thermal gradient estimated from the temperature measurements.

As excess heat in our experiments is associated with the hydrogen isotopes, subsequent measurements of temperatures on the sample and molybdenum base were carried out after filling the internal sample cavity with hydrogen isotopes, keeping the power of the glow discharge and parameters outside of the sample constant. The thermal flow from the sample was measured repeatedly using the formula above after stabilisation of parameters for 2-6h. Measurements were carried out at sample temperatures up to $1000 \mathrm{~K}$. The thermal flow from the sample was measured both with the internal sample cavity under vacuum, and filled with hydrogen isotopes, at identical discharge power, allowing for an estimation of the difference in thermal flow between the two cases. During measurements, we alternately pumped out the internal sample cavity. The discharge caused a constant flow of hydrogen isotopes from the discharge side through the sample wall to the inside, resulting in further loading hydrogen isotopes into the internal sample cavity up to a pressure of $6 \times 10^{3} \mathrm{~Pa}$.

This measurement philosophy assumes that the background level for excess heat is defined when the internal sample cavity is under vacuum. Such an approach probably overestimates the measured excess heat, as the influence of heat transmission inside the sample is not taken into account. The absolute error associated with the thermal flow measurements did not exceed $\pm 50 \%$ (relative $\pm 20 \%$ ). These measurements allow for only an estimate of the overall thermal balance. As further research has shown, the (unaccounted) heat loss in our system due to convection reduces the accuracy for estimations of the complete thermal balance. Given this, the technique is still useful, since it supposes a only a simple change associated with the sample; this is an important advantage at this stage of the research.

\section{Results}

\subsection{Results at different temperatures}

The basic results from experiments on the influence of a magnetic field on the tritium generation rate are shown in Table 1 . One sees that for cylindrical samples of molybdenum with thermal activation and natural mix of hydrogen isotopes, the resulting activity associated with the presence of tritium exceeded by about five times the activity of the initial hydrogen gas. For these samples, the excess activity from glow discharge experiments using a natural mix of hydrogen isotopes is seen to be greater at $1600 \mathrm{~K}$ than at $1800 \mathrm{~K}$, Experiments with water-cooled molybdenum samples at lower temperature (near $1000 \mathrm{~K}$ ) in natural hydrogen result in 
Table 1. Tritium generation from the interaction of the glow discharge plasma with metals, with and without a magnetic field.

\begin{tabular}{|c|c|c|c|c|c|c|c|c|c|c|c|}
\hline \multirow[b]{2}{*}{ metal, gas } & \multicolumn{7}{|c|}{ experimental parameters } & \multicolumn{2}{|c|}{ no field } & \multicolumn{2}{|c|}{ magnetic field } \\
\hline & $\begin{array}{l}T \\
\mathrm{~K}\end{array}$ & $\begin{array}{l}I \\
\mathrm{~A}\end{array}$ & $\begin{array}{l}V \\
\mathrm{~V}\end{array}$ & $\begin{array}{c}t \\
\mathrm{~h}\end{array}$ & $\begin{array}{c}P_{c} \\
\mathrm{~Pa} \\
\times 10^{3}\end{array}$ & $\begin{array}{c}P_{s} \\
\mathrm{~Pa} \\
\times 10^{3}\end{array}$ & $\begin{array}{c}\text { flow } \\
\mathrm{Mol} / \mathrm{s} \\
\times 10^{7}\end{array}$ & $\begin{array}{l}\text { act. } \\
\text { cps }\end{array}$ & $\begin{array}{c}\Gamma_{T} \\
\mathrm{~T} / \mathrm{s}\end{array}$ & $\begin{array}{l}\text { act. } \\
\text { cps }\end{array}$ & $\begin{array}{l}\Gamma_{T} \\
\mathrm{~T} / \mathrm{s}\end{array}$ \\
\hline $\mathrm{H}$ & & & & & & & & $\begin{array}{c}0.08 \\
\pm .04\end{array}$ & & $\begin{array}{c}0.08 \\
\pm .04\end{array}$ & \\
\hline Mo-23, H & 1800 & - & - & 46 & $\begin{array}{c}24 \\
-31\end{array}$ & $\begin{array}{c}120 \\
-170\end{array}$ & 1.2 & 0.5 & $8[5]$ & - & - \\
\hline Mo-23, H & 1600 & 3 & 600 & 31 & $\begin{array}{c}16 \\
-19\end{array}$ & $\begin{array}{c}149 \\
-167\end{array}$ & 0.6 & 1.3 & $2[6]$ & - & - \\
\hline Мo-100, H & 1020 & 3.1 & 410 & 6 & 6 & 6 & - & 40 & $9.7[7]$ & - & - \\
\hline Mo-100, He & 1255 & 2.9 & 395 & 6 & 5.6 & 5.6 & - & - & - & 0.1 & $1.8[5]$ \\
\hline, $\mathrm{H}$ & 1020 & 3.1 & 415 & 4 & 6 & 6 & - & - & - & 1700 & $6.1[9]$ \\
\hline $\mathrm{Nb}-100, \mathrm{H}$ & 1055 & 3.0 & 395 & 6 & 6 & 6 & - & 16 & $3.9[7]$ & - & - \\
\hline $\mathrm{Nb}-100, \mathrm{He}$ & 1280 & 2.9 & 440 & 6 & 6.6 & 6.6 & - & - & - & 5 & $7.9[6]$ \\
\hline, $\mathrm{H}$ & 1020 & 3.1 & 450 & 4 & 6.3 & 6.3 & - & - & - & 350 & $1.3[9]$ \\
\hline Ta-100, H & 1045 & 3.1 & 410 & 6 & 6 & 6 & - & 12 & $2.9[7]$ & - & - \\
\hline $\mathrm{Ta}-100, \mathrm{He}$ & 1270 & 3.0 & 445 & 6 & 6.5 & 6.5 & - & - & - & 4 & $6.1[6]$ \\
\hline, $\mathrm{H}$ & 1020 & 3.2 & 510 & 4 & 7.2 & 7.2 & - & - & - & 250 & $1.1[9]$ \\
\hline $\mathrm{W}-100, \mathrm{H}$ & 1030 & 3.1 & 445 & 6 & 6 & 6 & - & 27 & $6.5[7]$ & - & - \\
\hline $\mathrm{W}-100, \mathrm{He}$ & 1300 & 2.8 & 425 & 6 & 7.8 & 7.8 & - & - & - & 0.1 & $1.9[5]$ \\
\hline, $\mathrm{H}$ & 1005 & 3.1 & 490 & 6.5 & 8 & 8 & - & - & - & 3200 & $9.4[9]$ \\
\hline
\end{tabular}

$\bar{T}$ is temperature (K), $I$ is the current $(\mathrm{A}), V$ is voltage $(\mathrm{V}), t$ is run time $(\mathrm{h}), P_{c}$ is the cell pressure $\left(\mathrm{Pa} \times 10^{3}\right), P_{s}$ is the sample temperature $\left(\mathrm{Pa} \times 10^{3}\right)$, act. denotes the tritium activity in counts/sec, and $\Gamma_{T}$ is the tritium production rate in atoms/sec. Powers of 10 indicated with brackets; 6.1[9] $=$ $6.1 \times 10^{9}$.

even greater activity, about a factor of 50 higher than the initial gas activity. This is probably connected to the further reduction of the sample temperature, which in subsequent experiments did not exceed $1300 \mathrm{~K}$. We note that a the surface concentration hydrogen isotopes is increased at the lower temperatures. It is possible that the increase of activity is also connected to the influence the electric field distribution, the self-magnetic field, and to the interaction of hydrogen isotopes with the sputtered atoms from the flat metal sample.

The introduction of the magnetic field perpendicular to the molybdenum sample surface with other parameters comparable has resulted in an additional increase of activity (and the tritium generation rate) of almost another two orders of magnitude. 
Table 2. Tritium generation associated with the interaction of hydrogen isotopes with different metals in a glow discharge with a magnetic field imposed.

\begin{tabular}{|c|c|c|c|c|c|c|c|c|}
\hline \multirow[t]{3}{*}{ Material } & \multicolumn{5}{|c|}{ experimental parameters } & \multicolumn{3}{|c|}{ results } \\
\hline & $T$ & $I$ & $V$ & $t$ & $P_{c}$ & act. & $\Gamma_{T}$ & Coefficient of \\
\hline & $\mathrm{K}$ & A & $\mathrm{V}$ & $\mathrm{h}$ & $\begin{array}{c}\mathrm{Pa} \\
\times 10^{3}\end{array}$ & $\operatorname{cps}$ & atom/s & $\begin{array}{c}\text { nuclear interaction } \\
\text { atom/ion }\end{array}$ \\
\hline $99.985 \% \mathrm{H}_{2}$ & & & & & & 0.08 & & \\
\hline$+0.015 \% \mathrm{D}_{2}$ & & & & & & \pm 0.04 & & \\
\hline $\mathrm{Ti}$ & 1090 & 3.1 & 410 & 4.1 & 7.4 & 140 & $6.3 \times 10^{8}$ & $5.3 \times 10^{-11}$ \\
\hline $0.85 \mathrm{Ti}$ & 1170 & 3.1 & 385 & 4 & 6.2 & 2000 & $7.5 \times 10^{9}$ & $6.3 \times 10^{-10}$ \\
\hline$+0.15 \mathrm{Pt}$ & & & & & & & & \\
\hline \multirow[t]{2}{*}{ V } & 1170 & 3.1 & 405 & 5 & 7.4 & 750 & $2.7 \times 10^{9}$ & $2.4 \times 10^{-10}$ \\
\hline & 1260 & 3.1 & 390 & 4 & 14.4 & 47 & $4.1 \times 10^{8}$ & $3.7 \times 10^{-11}$ \\
\hline \multirow[t]{3}{*}{$\mathrm{Nb}$} & 1060 & 3.1 & 395 & 6 & 3 & 12 & $1.5 \times 10^{7}$ & $1.3 \times 10^{-12}$ \\
\hline & 1020 & 3.1 & 450 & 4 & 6.3 & 340 & $1.3 \times 10^{9}$ & $1.1 \times 10^{-10}$ \\
\hline & 1170 & 3.1 & 465 & 4 & 14.2 & 11 & $9.5 \times 10^{7}$ & $8.3 \times 10^{-12}$ \\
\hline \multirow[t]{3}{*}{ Mo } & 990 & 3.1 & 400 & 6 & 3 & 17 & $2.1 \times 10^{7}$ & $1.8 \times 10^{-12}$ \\
\hline & 1020 & 3.1 & 415 & 4 & 6 & 1700 & $6.1 \times 10^{9}$ & $5 \times 10^{-10}$ \\
\hline & 1290 & 3.1 & 525 & 8.5 & 16 & 330 & $1.5 \times 10^{9}$ & $1.3 \times 10^{-10}$ \\
\hline \multirow[t]{2}{*}{$\mathrm{Ta}$} & 1020 & 3.2 & 510 & 4 & 7.2 & 255 & $1.1 \times 10^{9}$ & $9.3 \times 10^{-11}$ \\
\hline & 1180 & 3.1 & 430 & 4 & 14.2 & 17 & $1.5 \times 10^{8}$ & $1.3 \times 10^{-11}$ \\
\hline \multirow[t]{5}{*}{ W } & 1060 & 3.2 & 395 & 6 & 3 & 8 & $9.7 \times 10^{6}$ & $8.2 \times 10^{-13}$ \\
\hline & 1005 & 3.1 & 490 & 6.5 & 8 & 3200 & $9.4 \times 10^{9}$ & $8.3 \times 10^{-10}$ \\
\hline & 1255 & 3.1 & 530 & 8.5 & 14.8 & 658 & $2.8 \times 10^{9}$ & $2.4 \times 10^{-10}$ \\
\hline & 1470 & 3.0 & 680 & 8 & 30.6 & 229 & $2.1 \times 10^{9}$ & $1.9 \times 10^{-10}$ \\
\hline & 670 & 1.9 & 360 & 4 & 6 & 3 & $1.1 \times 10^{7}$ & $1.5 \times 10^{-12}$ \\
\hline $\mathrm{Pb}$ & 620 & 1.9 & 350 & 4 & 6 & 24 & $8.7 \times 10^{7}$ & $1.2 \times 10^{-11}$ \\
\hline
\end{tabular}

\subsection{Metal surface effects}

The use of inert helium in the (plasma-forming) gas for experiments on flat samples of molybdenum, with a water-cooled substrate and magnetic field, results in values of tritium activity close to background. A similar value was seen in the case of tungsten. For materials such as niobium and tantalum, the tritium activity with inert helium has increased by more than an order of magnitude, in comparison with molybdenum and tungsten. This could be connected to residual hydrogen, the quantity of which is greater in hydride-forming metals.

The tritium generation rate for flat samples with a natural mix of hydrogen isotopes for flat samples in the glow discharge in the absences of a magnetic field were within the range of $2.9 \times 10^{7}-9.7 \times 10^{7}$ atom/s for the metals tested. This is almost two orders of magnitude greater than the background rate one would associated with the initial hydrogen gas activity. For such conditions the tritium generation rate for molybdenum and tungsten are seen to be somewhat greater than for niobium 


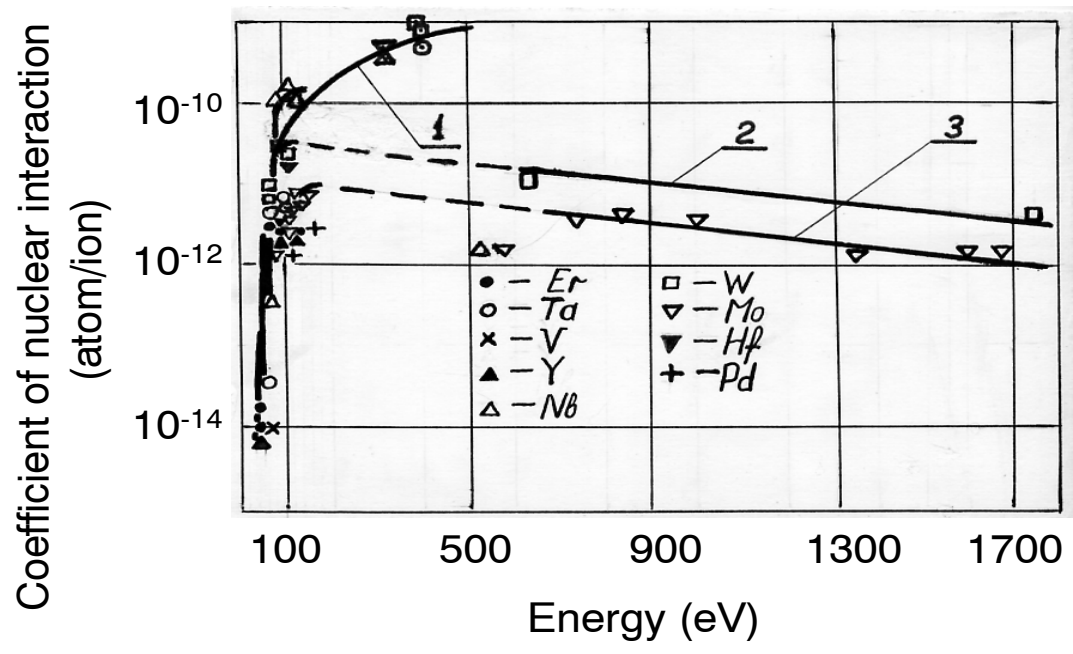

Figure 4. Dependence of the coefficient of nuclear interactions versus an energy of ions for hydrogen isotopes in the glow discharge. 1: Dependence for $\mathrm{Nb}, \mathrm{Mo}$, Ta and $\mathrm{W}$, received from results of present works; 2 : earlier received dependence for $\mathrm{W} ; 3$ : earlier received dependence for Mo. ${ }^{3}$

and tantalum. This may be connected to the interaction of hydrogen isotopes with the metal surface, since the presence of dissolved hydrogen at the surface changes the physical characteristics; for example, softening the impact during collisions of isotopes with the surface and connecting with surface electrons.

\subsection{Results with a magnetic field}

The introduction of a magnetic field in the region where the the glow discharge plasma interacts with the metal surface has allowed us to achieve tritium generation rates in the range of $1.1 \times 10^{9}-9.4 \times 10^{9}$ atom $/ \mathrm{s}$, for all of the metals investigated with a natural mix of hydrogen isotopes. The largest tritium generation rate is found in the case of tungsten. As was the case for no magnetic field, the tritium production rate is higher for molybdenum and tungsten than for niobium and tantalum.

\subsection{Results at different pressures}

Results for experiments focused on the dependence of the tritium generation rate on gas pressure are given in Table 2. From this table it is possible to see the influence of pressure, and other parameters, on the tritium generation rate already more clearly than was presented previously (see Refs. 8 and 9).

\subsection{Dependence on deuteron ion energy}

It is not possible to define precisely the deuteron energy required for tritium generation from the results. From the results shown in Figure 4 (see [3]), the threshold 


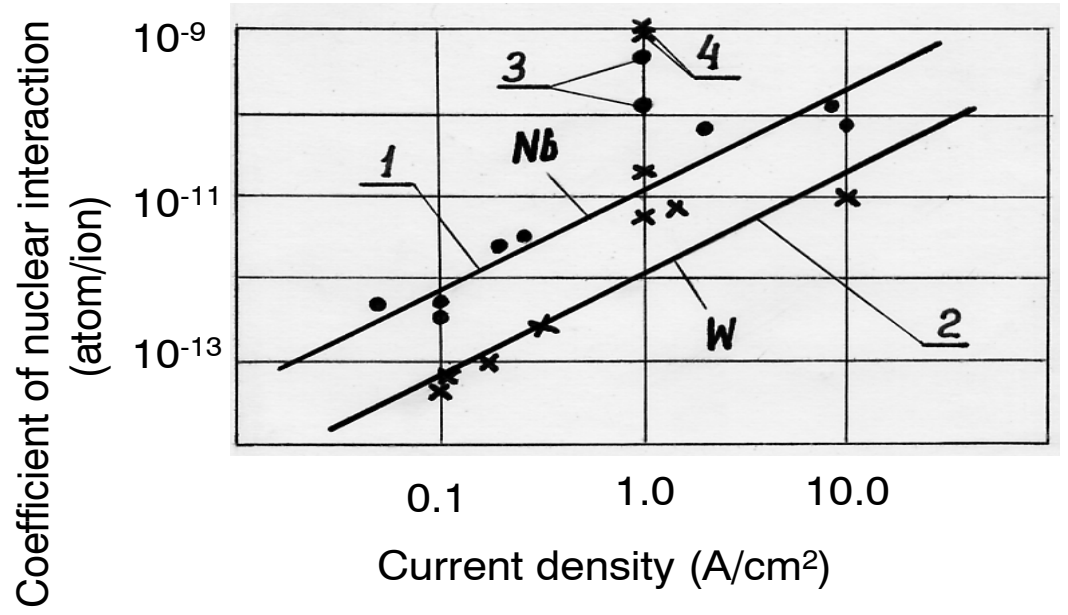

Figure 5. Dependence for coefficient of nuclear interaction versus of a current density in the glow discharge for $\mathrm{Nb}$ and $\mathrm{W} ; 1$ : niobium $\left(\mathrm{D}_{2}\right) ; 2$ : tungsten $\left(\mathrm{D}_{2}\right) ;{ }^{2} 3$ : niobium $\left(\mathrm{H}_{2}\right) ; 4$ : tungsten $\left(\mathrm{H}_{2}\right)$; present work.

energy can be defined roughly; in this case the energy is $100 \mathrm{eV}$. A reduction in the tritium generation rate for energies above $100 \mathrm{eV}$ is apparent in curves 2 and 3 of this figure; this reduction is associated with a reduction of the current density at low pressure, and a reduction of the ion energy at increased pressure and voltage. In the case of tungsten, an increase of the voltage from $360 \mathrm{~V}$ up to $490 \mathrm{~V}$, and a corresponding increase in the current (and hence current density) from 1.9 to $3.1 \mathrm{~A}$, results in an increase of the tritium generation rate from $1.1 \times 10^{7}$ atom $/ \mathrm{s}$ up to $9.4 \times 10^{9} \mathrm{atom} / \mathrm{s}$ (almost on three orders of magnitude). It is possible to conclude from these results that the voltage reduction for the discharge down to $400 \mathrm{~V}$ or below is not expedient. The increase in the tritium generation rate with a decrease in pressure to $(6-8) \times 10^{3} \mathrm{~Pa}$ for all materials supports this conclusion. In spite of the fact that at reduced pressure for some materials (molybdenum, tungsten) the voltage fell, an increase in the tritium generation rate was observed; this can be attributed to a decrease of the energy loss due to collisions at the lower pressure. This increase in rate occurred even at a significant reduction of the current density (which has a square law dependence on pressure). Thus it is desirable that the ion energy be much higher $100 \mathrm{eV}$, according to the dependence exhibited in curve 1 .

\subsection{Dependence on ion flux}

An increase in the deuteron ion energy and flux results in an increase of the tritium generation rate. The dependence of the tritium generation rate is monotonic in the current density, with a power law dependence in the range of 1.2-1.5 (see Fig. 5), was found previously ${ }^{9.11}$

The present results show that there exists an optimum ratio of ion energy and 
current density. For a decrease of pressure in the case of tungsten from $30.6 \times 10^{3} \mathrm{~Pa}$ down to $8 \times 10^{3} \mathrm{~Pa}$ (and a corresponding reduction of the current density, a factor of approximately 14), the increase in ion energy (even with a reduction in voltage) results in an increase of the tritium generation rate from $2.1 \times 10^{9} \mathrm{atom} / \mathrm{s}$ up to $9.4 \times 10^{9}$ atom/s. However, with a further pressure decrease (approximately twofold) down to $3 \times 10^{3} \mathrm{~Pa}$, the tritium generation rate falls on the order of 2-3 orders of magnitude for $\mathrm{Nb}, \mathrm{Mo}, \mathrm{W}$. The average current density in this case is lower by a factor of 4 . The current density at a pressure of $8 \times 10^{3} \mathrm{~Pa}$ is about $1 \mathrm{~A} / \mathrm{cm}^{2}$, with a power law dependence in the range $3-4$, which may be considered as the the optimum for experiments on the tritium generation.

\subsection{Temperature of the target-anvil}

In the case of thermal activation, the appearance of tritium exhibits an exponential dependence of temperature. ${ }^{5}$ A similar dependence of the rate of tritium production is not present in these glow discharge experiments. At the same time, the results for tungsten and lead obtained at lower voltage and current (two last lines of Table 4) are disproportionately low, which indicates a negative influence on the tritium generation rate for temperatures is lower than $700-800 \mathrm{~K}$. It is clear that the optimum temperatures lay in a range from 900 to $1300 \mathrm{~K}$, as at higher temperatures the ion energy is reduced (due to thermo-emission).

\subsection{Dependence on pressure}

The optimum pressure in the present experiments is in the range $6 \times 10^{3} \mathrm{~Pa}$ to $8 \times 10^{3} \mathrm{~Pa}$ (see Fig. 6), which can be compared to previous results. ${ }^{8,11}$ The main feature of the present experiments is that the optimum pressure was the same for all metals. The further decrease of pressure below the peak results in a significant reduction of the tritium generation rate because due primarily to the decrease of current density, where the increase in ion energy does not compensate the decrease in current density [see curves 8,9]. For niobium, molybdenum, and tungsten, the reduction of the tritium generation rate is two to three orders of magnitude.

A decrease in pressure is possible only if the average current density is not lower than $0.1 \AA / \mathrm{cm}^{2}$. It is known that the braking action of the residual gases results in a decrease of the energy of accelerated ions, an effect which is reduced considerably at pressures less than (10-50) Pa. It is clear then that the pressure in the range of 10 to $50 \mathrm{~Pa}$ will be optimum; however, the current density specified above must be maintained. The maximum pressure should not exceed $2 \times 10^{4} \mathrm{~Pa}$ because of a decrease in ion energy, and even an increase in the discharge voltage.

\subsection{Material of the target-anvil}

Satisfactory agreement of the tritium generation rate with predictions made earlier is obtained. ${ }^{12}$ The highest tritum generation rates are found in the case of heavier 


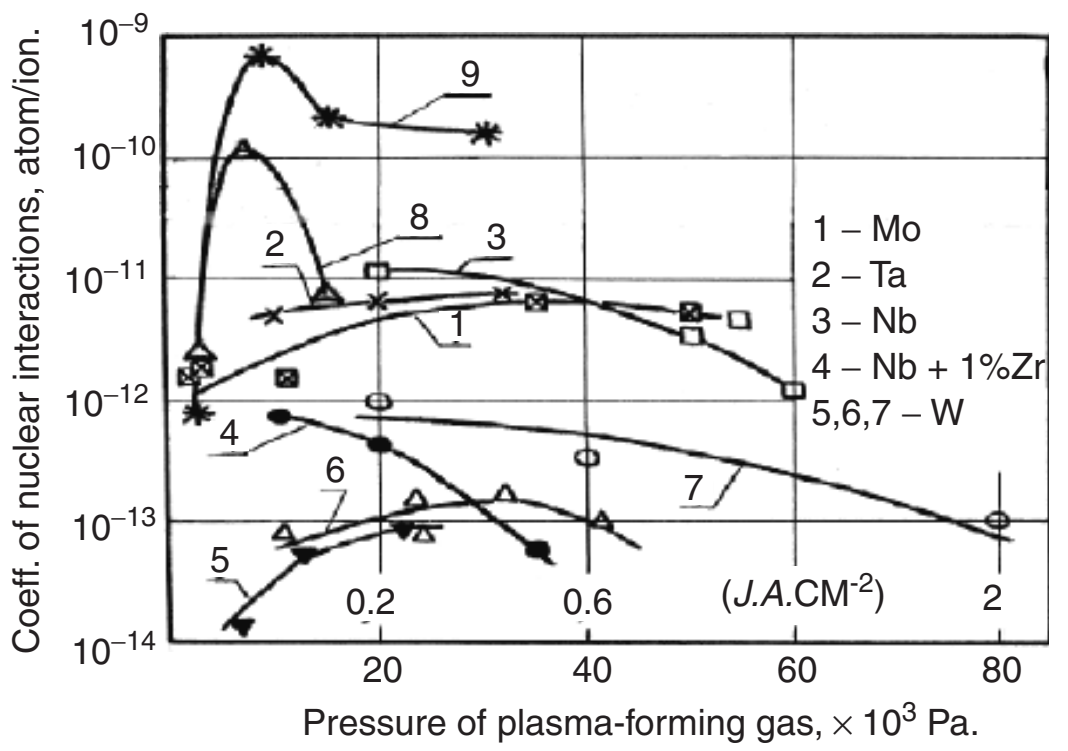

Figure 6. Dependence of coefficient of nuclear interaction versus on pressure of plasma-forming gas in the glow discharge for various materials of the sample-cathode; 1 : molybdenum $\left(\mathrm{D}_{2}\right) ; 2$ : tantalum $\left(\mathrm{D}_{2}\right) ; 3$ : niobium $\left(\mathrm{D}_{2}\right) ; 4$ : niobium $+1 \%$ of zirconium $\left(\mathrm{D}_{2}\right) ; 5,6,7$ : tungsten $\left(\mathrm{D}_{2}\right) ; 8$ : niobium $\left(\mathrm{H}_{2}\right)$; 9: tungsten $\left(\mathrm{H}_{2}\right)$; present work.

metals, such as tungsten and platinum. Prospective materials include hafnium, tantalum, osmium, iridium, and gold. It is also possible to consider for use even heavier metals such as lead, bismuth, thorium, and uranium.

\subsection{Plasma-forming gas}

It is shown in [13] that the tritium generation rate for a mix of hydrogen isotopes based on hydrogen, and a mix based on deuterium, does not exceed one order of magnitude. This implies that the $\mathrm{p}+\mathrm{d}$ reaction mechanism for tritium formation (which is discussed later on in this paper) is a secondary reaction as compared to the primary $\mathrm{p}+\mathrm{p}$ reaction that leads to deuterium formation (also discussed later on), with an associated reaction rate approximately six orders of magnitude smaller. Therefore, from the point of view of efficiency, the use of easier isotopes for excess heat production and for tritium generation is the the most important factor.

\subsection{Magnetic field}

It is possible to conclude from diefferent results obtained for coaxial and planar experimental systems that the self-magnetic field influences the tritium generation rate. The introduction of an external magnetic field of $0.02-0.2 \mathrm{~T}$ on the discharge system has allowed us to increase the rate for tritium generation by two orders of magnitude. ${ }^{14}$ A careful study of the influence of intensity, gradient, form of 


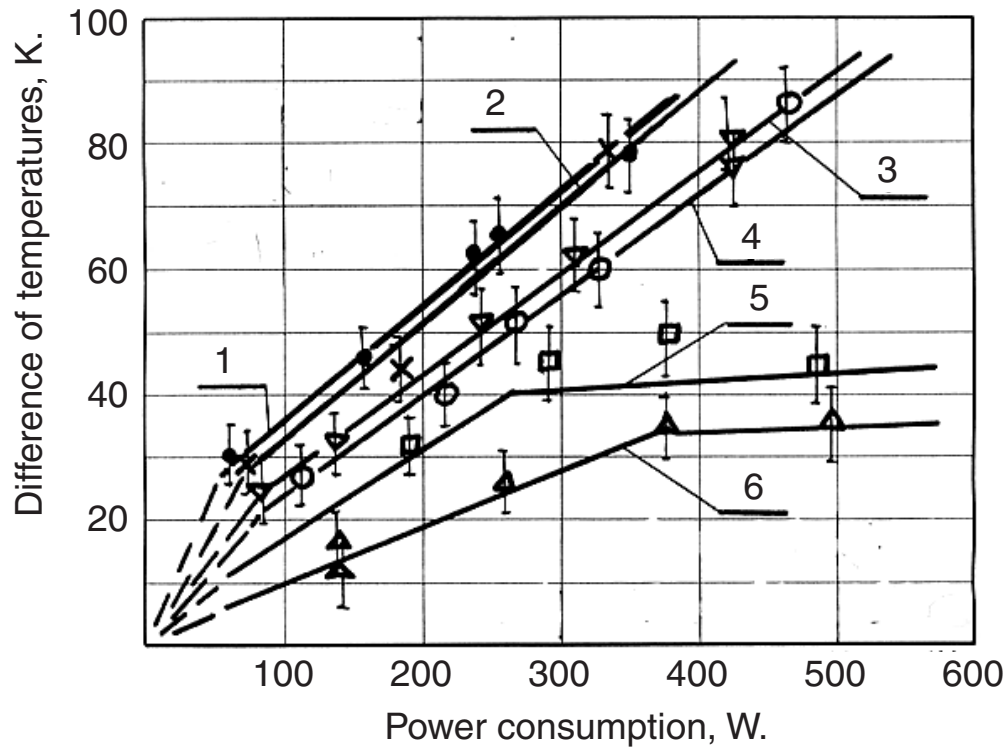

Figure 7. Dependence for difference of the temperatures, on measuring base, versus total a power consumption for hollow sample of vanadium with diameter of $40 \mathrm{~mm}$, height of $60 \mathrm{~mm}$ and thickness of the wall of $2 \mathrm{~mm}$. 1: Sample-cathode, hydrogen, $P_{\mathrm{c}}=P_{\mathrm{sam}}=5000 \mathrm{~Pa} ; 2$ : sample-cathode, hydrogen, $P_{\mathrm{c}}=P_{\mathrm{sam}}=10,000 \mathrm{~Pa}$; 3 : sample-cathode, hydrogen, $P_{\mathrm{c}}=P_{\mathrm{sam}}=2000 \mathrm{~Pa}$; 4 : samplecathode, deuterium, $P_{\mathrm{c}}=P_{\mathrm{sam}}=2000 \mathrm{~Pa} ; 5$ : sample-anode, deuterium, $P_{\mathrm{c}}=P_{\mathrm{sam}}=2000 \mathrm{~Pa} ; 6$ : sample-anode, hydrogen, $P_{\mathrm{c}}=P_{\mathrm{sam}}=2000 \mathrm{~Pa}$.

distribution, polarity, and other characteristics of the magnetic field on the discharge parameters to obtain a further increase of efficiency to the discharge system.

\subsection{Energy balance}

The dependence of the temperatures difference on the molybdenum (measuring) base (and hence the thermal flow from the sample) on the total power for a hollow vanadium sample with a diameter of $40 \mathrm{~mm}$, a height of $60 \mathrm{~mm}$, and a wall thickness of $2 \mathrm{~mm}$, for $P_{\mathrm{c}}=P_{\mathrm{sam}}$ (background), is shown in Fig. 7. One can see an inflection in the curves at small temperature differences and low power (about 50-70 W), which is similar to [3]. This effect, in our opinion, is connected to the onset of convective heat transfer. It is necessary to keep in mind that at reduced pressure the sample temperature (and hence temperature difference) is increased (see curves $1,2)$, because of a reduction in the convective heat transfer. In this connection, the smaller temperature difference for a pressure of $2000 \mathrm{~Pa}$ (see curves 3,4 ) are caused by a change of the design used for this pressure. This is due to a difference in the approach used for the measurement of the anode temperature, where the distance between the thermocouples and anode was changed.

For experiments in which the sample is the cathode, the distinction in differences of temperatures for protium and deuterium is not great (curves 3 and 4). In experiments in hydrogen in which the sample is the anode, the heat absorbed 


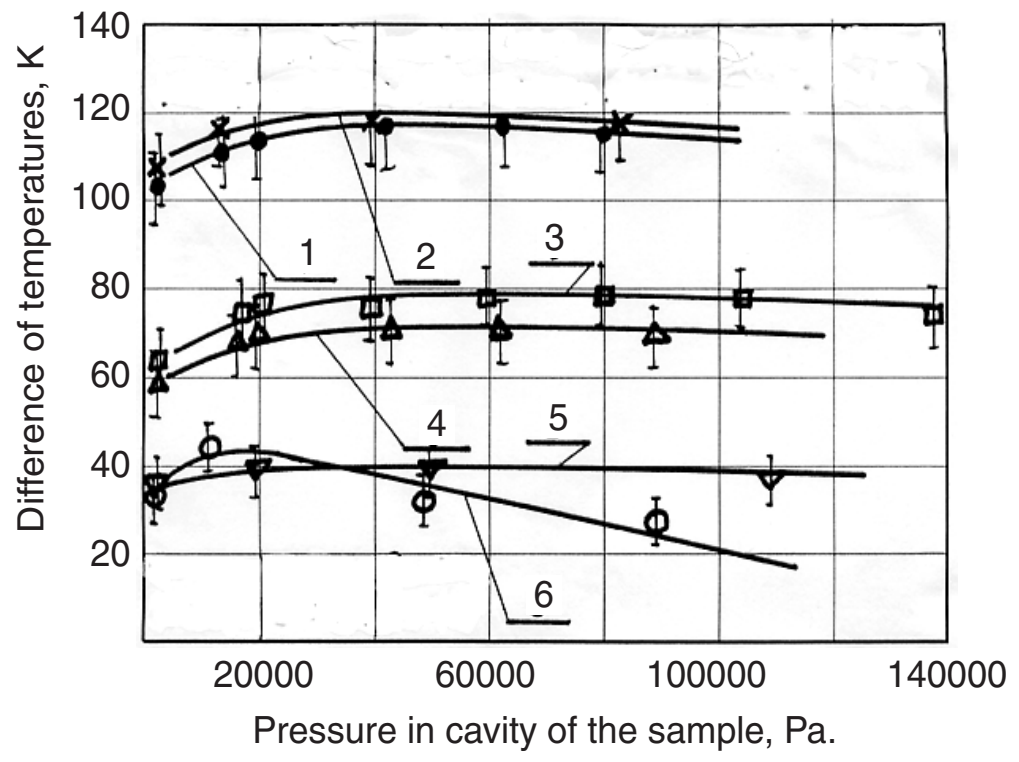

Figure 8. Dependence of difference of temperatures on measuring base versus pressure of the natural mix of hydrogen isotopes in a cavity of the sample (hollow sample of vanadium, diameter of $40 \mathrm{~mm}$, height of $60 \mathrm{~mm}$ and thickness of a wall of $2 \mathrm{~mm}$ ). 1: Sample-cathode, $E=820 \mathrm{~W}$, $P_{\mathrm{c}}=10000 \mathrm{~Pa}, T=840 \mathrm{~K} ; 2$ : sample-cathode, $E=770 \mathrm{~W}, P_{\mathrm{c}}=10,000 \mathrm{~Pa}, T=850 \mathrm{~K}$; 3 : samplecathode, $E=396 \mathrm{~W}, P_{\mathrm{c}}=10,000 \mathrm{~Pa}, T=680 \mathrm{~K} ; 4:$ sample-anode, $E=769 \mathrm{~W}, P_{\mathrm{c}}=10000 \mathrm{~Pa}$, $T=695 \mathrm{~K} ; 5$ : sample-cathode, $E=252 \mathrm{~W}, P_{\mathrm{c}}=20,000 \mathrm{~Pa}, T=535 \mathrm{~K} ; 6$ : sample-anode, $E=388 \mathrm{~W}, P_{\mathrm{c}}=10,000 \mathrm{~Pa}, T=550 \mathrm{~K}$.

is approximately half as much as in experiments where the sample is the cathode (see curves 3,6 ). In experiments in deuterium, this difference is not as significant (see curves 4 and 5). The data obtained allow us to make a thermal balance of the distribution of heat in the discharge. For example, in a discharge plasma at $2000 \mathrm{~Pa}$ and interelectrode distance $5 \mathrm{~mm}$, about $10 \%$ of the total power is lost in the glow discharge plasma. From the results shown in Fig. 7, it is possible to find that for a hydrogen discharge with the sample as cathode, about $60 \%$ of heat is dissipated on the cathode and about $30 \%$ of heat is dissipated on the anode.

The dependence of the base temperature difference (and hence the power absorbed by the sample) on the internal pressure of the sample cavity is shown in Fig. 8. One can see a flat maximum in (0.04-0.1) MPa for the different experimental conditions. An additional thermal flux occurs on the sample when filled by hydrogen, irrespective whether the sample is the cathode or anode. Hence, to obtain an identical thermal flux, the discharge power should be increased by two when the sample is an anode (as compared to when the sample is a cathode, see curves 3-6). 
Table 3. Measurement of the excess heat flow in the glow discharge with a natural mix of hydrogen isotopes with forward and reverse flows of hydrogen through the wall of the cathode sample.

\begin{tabular}{|c|c|c|c|c|c|c|c|c|}
\hline $\begin{array}{l}P_{d} \\
\mathrm{~W} \\
\end{array}$ & $\begin{array}{c}P_{c} \\
\times 10^{-3} \mathrm{~Pa} \\
\end{array}$ & $\begin{array}{c}P_{s} \\
\times 10^{-3} \mathrm{~Pa} \\
\end{array}$ & $\begin{array}{l}T_{t} \\
\mathrm{~K} \\
\end{array}$ & $\begin{array}{c}\Delta T \\
\mathrm{~K} \\
\end{array}$ & $\begin{array}{l}T_{s} \\
\mathrm{~K}\end{array}$ & $\begin{array}{c}P_{a b s}(K) \\
\mathrm{W} \\
\end{array}$ & $\begin{array}{c}P_{x s} \\
\mathrm{~W} \\
\end{array}$ & $\begin{array}{c}P_{x s} / P_{a b s} \\
\% \\
\end{array}$ \\
\hline \multirow{2}{*}{210} & 10 & 44 & 430 & 41 & 525 & 10.3 & 0.5 & 5 \\
\hline & 10 & $10^{-3}$ & 425 & 39 & 540 & 9.8 & - & - \\
\hline \multirow[t]{2}{*}{256} & 10 & 90 & 455 & 52 & 570 & 13.1 & 2.0 & 18 \\
\hline & 10 & $10^{-3}$ & 435 & 44 & 575 & 11.1 & - & - \\
\hline \multirow[t]{2}{*}{284} & 10 & 65 & 460 & 57 & 580 & 14.3 & 2.3 & 19 \\
\hline & 10 & $10^{-3}$ & 450 & 48 & 590 & 12.0 & - & - \\
\hline \multirow[t]{2}{*}{396} & 10 & 108 & 530 & 80 & 690 & 19.9 & 4.5 & 29 \\
\hline & 10 & $10^{-3}$ & 490 & 62 & 680 & 15.4 & - & - \\
\hline \multirow[t]{2}{*}{525} & 10 & 43 & 555 & 90 & 730 & 22.2 & 2.5 & 13 \\
\hline & 10 & $10^{-3}$ & 520 & 80 & 730 & 19.7 & - & - \\
\hline \multirow[t]{2}{*}{532} & 10 & 38 & 550 & 86 & 710 & 21.2 & 2.2 & 12 \\
\hline & 10 & $10^{-3}$ & 525 & 77 & 720 & 19.0 & - & - \\
\hline \multirow[t]{2}{*}{658} & 11 & 50 & 600 & 108 & 820 & 26.2 & 3.4 & 15 \\
\hline & 11 & $10^{-3}$ & 570 & 94 & 820 & 22.8 & - & - \\
\hline \multirow[t]{2}{*}{798} & 11 & 90 & 605 & 109 & 810 & 26.4 & 3.1 & 13 \\
\hline & 11 & $10^{-3}$ & 575 & 96 & 820 & 23.3 & - & - \\
\hline \multirow[t]{2}{*}{820} & 10 & 62 & 625 & 118 & 840 & 28.6 & 3.9 & 16 \\
\hline & 10 & $10^{-3}$ & 590 & 102 & 840 & 24.7 & - & - \\
\hline
\end{tabular}

$P_{d}$ is the discharge power $(\mathrm{W}) ; P_{c}$ is the chamber pressure $\left(\times 10^{-3} \mathrm{~Pa}\right) ; P_{s}$ is the internal sample pressure $\left(\times 10^{-3} \mathrm{~Pa}\right) ; T_{t}$ is the temperature of top hold-down; $\Delta T$ is the difference of base temperatures $(\mathrm{K}) ; T_{s}$ is the sample temperature; $P_{a b s}$ is the power absorbed by the sample (W); $P_{x s}$ is the excess power; $P_{x s} / P_{d}$ is the ratio of excess power to the power absorbed by the sample

\subsection{Excess heat measurements}

Measurements of the excess heat flow from the cathode sample for a natural mix of hydrogen isotopes ( $99.985 \%$ protium $+0.015 \%$ deuterium) are presented in Table 3 . One sees that the excess power is sharply increased with a temperature rise up to 600-700 K; beyond that there is little change. The relative excess power reached $29 \%$ from everything absorbed by a sample; for example, at a total discharge power of $396 \mathrm{~W}$, the sample got $396 \times 0.6=238 \mathrm{~W}$, and thus the absolute values of excess power is $(238 \times 0.29=69)$, or about $70 \mathrm{~W}$. As compared to all of the power dissipated by the glow discharge, this excess power is about $10 \%$. The maximum relative values of the excess heat were observed in the temperature range $600-700 \mathrm{~K}$.

Results for a study of the excess thermal flux for deuterium, and for a natural mix of a hydrogen isotopes (protium $+0.015 \%$ deuterium), are shown in Table 4 . 
Table 4. Comparison of the excess heat between deuterium and a natural mix of hydrogen isotopes, for glow discharge experiments with forward and reverse flows of hydrogen through the wall of the cathode sample.

\begin{tabular}{|c|c|c|c|c|c|c|c|c|c|c|}
\hline $\begin{array}{l}\text { cathode/ } \\
\text { anode }\end{array}$ & gas & $\begin{array}{l}P_{d} \\
\mathrm{~W}\end{array}$ & $\begin{array}{c}P_{c} \\
\times 10^{-3} \mathrm{~Pa}\end{array}$ & $\begin{array}{c}P_{s} \\
\times 10^{-3} \mathrm{~Pa}\end{array}$ & $\begin{array}{l}T_{t} \\
\mathrm{~K}\end{array}$ & $\begin{array}{c}\Delta T \\
\mathrm{~K}\end{array}$ & $\begin{array}{l}T_{s} \\
\mathrm{~K}\end{array}$ & $\begin{array}{c}P_{a b s} \\
W\end{array}$ & $\begin{array}{c}P_{x s} \\
W\end{array}$ & $\begin{array}{c}P_{x s} / P_{a b s} \\
\%\end{array}$ \\
\hline \multirow[t]{4}{*}{ cathode } & $\overline{\mathrm{H}}$ & 430 & 2.5 & 83 & 487 & 84 & 733 & 21.0 & 2.5 & 13 \\
\hline & & 430 & 3 & $\times 10^{-3}$ & 475 & 74 & 715 & 18.5 & - & - \\
\hline & D & 463 & 2.8 & 43 & 508 & 92 & 811 & 22.8 & 1.5 & 7 \\
\hline & & 463 & 2.8 & $\times 10^{-3}$ & 493 & 86 & 813 & 21.3 & - & - \\
\hline \multirow[t]{4}{*}{ anode } & $\mathrm{H}$ & 975 & 2.3 & 80 & 468 & 66 & 728 & 16.6 & 1.5 & 10 \\
\hline & & 975 & 2.3 & $\times 10^{-3}$ & 458 & 60 & 730 & 15.1 & - & - \\
\hline & D & 851 & 4 & 50 & 446 & 50 & 666 & 12.6 & 1.3 & 11 \\
\hline & & 837 & 4 & $\times 10^{-3}$ & 441 & 45 & 663 & 11.3 & - & - \\
\hline
\end{tabular}

$P_{d}$ is the discharge power $(\mathrm{W}) ; P_{c}$ is the chamber pressure $\left(\times 10^{-3} \mathrm{~Pa}\right) ; P_{s}$ is the internal sample pressure $\times 10^{-3} \mathrm{~Pa} ; T_{t}$ is the emperature of top-hold-down $(\mathrm{K}) ; \Delta T$ is the temperature difference of the base; $T_{s}$ is the sample temperature $(\mathrm{K}) ; P_{a b s}$ is the power absorbed by the sample $(\mathrm{W}) ; P_{x s}$ is the excess power; $P_{x s} / P_{d}$ is the ratio of excess power to the power absorbed by the sample

For simplification of accounts in case of the scheme which inclusion the sampleanode, both for protium and for deuterium accepted, that from consumption power of the discharge the $30 \%$ of this power is absorbed by a sample. It is visible, that the excess power in experiments with deuterium under identical conditions is comparable to excess power received in experiments with a natural mix of the hydrogen isotopes. The excess thermal flows at identical temperatures of samples with protium and deuterium are comparable as in experiments, when the sample is the cathode and in experiments, when the sample is the anode.

\subsection{Tritium generation}

The dependence of the tritium generation rate on the composition of the plasmaforming gas is shown in Table 5, where results are given for a natural mix of hydrogen isotops, and for mixtures containing about $10 \%$ deuterium by volume. The use of a magnetic field in the interaction zone where the glow discharge plasma interacts with the metal surface allowed us to reach a maximum tritium generation rate of $10^{10} \mathrm{atom} / \mathrm{s}$. This maximum rate was observed in experiments with tungsten. The addition of deuterium at the $10 \%$ level is seen to produce a further increase in the tritium generation rate. This increase is about $10-20 \%$ for molybdenum and tungsten; for niobium and tantalum the increase of the tritium generation rate is much larger, by a factor of 4 to 7 . This increase in the tritium generation rate did not correspond to the increase in the deuterium concentration (which in all cases was increased by almost $4-5$ orders of magnitude). The determination of why there should be such a difference will be the subject of future research. 
Table 5. Results for the dependence of the tritium generation rate on gas composition and sample material for glow discharge experiments in a magnetic field.

\begin{tabular}{|c|c|c|c|c|c|c|c|c|c|c|}
\hline \multirow{3}{*}{ metal } & \multicolumn{2}{|c|}{ gas } & \multicolumn{5}{|c|}{ experimental parameters } & \multicolumn{3}{|c|}{ experimental results } \\
\hline & $\mathrm{H}$ & D & $T$ & $I$ & $V$ & $t$ & $P_{c}$ & act. & $\Gamma_{T}$ & yield \\
\hline & $\%$ & $\%$ & K & A & V & $\mathrm{h}$ & $\mathrm{Pa} \times 10^{3}$ & cps & $\mathrm{T} / \mathrm{s}$ & $\mathrm{T} /$ ion \\
\hline \multirow[t]{2}{*}{$\overline{\mathrm{H}}$} & 99.985 & 0.015 & & & & & & 0.08 & & \\
\hline & & & & & & & & \pm 0.04 & & \\
\hline \multirow{2}{*}{$\mathrm{D}$} & 5 & 95 & & & & & & 0.3 & & \\
\hline & & & & & & & & \pm 0.15 & & \\
\hline \multirow[t]{2}{*}{ SS } & 99.985 & 0.015 & 1020 & 3.1 & 415 & 4 & 6 & 170 & $6.1[8]$ & $5.3[-11]$ \\
\hline & 91 & 9 & 870 & 3.1 & 400 & 3 & 5.7 & 370 & $1.7[9]$ & $1.5[-10]$ \\
\hline \multirow[t]{2}{*}{$\mathrm{Nb}$} & 99.985 & 0.015 & 1020 & 3.1 & 450 & 4 & 6.3 & 350 & $1.3[9]$ & $1.1[-10]$ \\
\hline & 90 & 10 & 920 & 3.1 & 420 & 4 & 5.8 & 1200 & $4.1[9]$ & $3.5[-10]$ \\
\hline \multirow[t]{2}{*}{ Mo } & 99.985 & 0.015 & $1020-1200$ & 3.0 & 335 & 2 & 5.5 & 10 & $6.7[7]$ & $5.9[-12]$ \\
\hline & 91 & 9 & $1050-1190$ & 3.1 & 355 & 4 & 5.6 & 25 & $8.5[7]$ & $7.3[-12]$ \\
\hline \multirow[t]{2}{*}{ Mo } & 99.985 & 0.015 & 1020 & 3.2 & 510 & 4 & 7.2 & 250 & $1.1[9]$ & $9.3[-11]$ \\
\hline & 87 & 13 & 920 & 3.2 & 515 & 4 & 6 & 2160 & $7.8[9]$ & $6.6[-10]$ \\
\hline \multirow[t]{2}{*}{ W } & 99.985 & 0.015 & 1005 & 3.1 & 490 & 6.5 & 8 & 3160 & $9.4[9]$ & $8.3[-10]$ \\
\hline & 87 & 13 & 920 & 3.2 & 475 & 4 & 6 & 3100 & $1.1[10]$ & $9.5[-10]$ \\
\hline
\end{tabular}

\subsection{Mass spectroscopy}

We showed previously ${ }^{1}$ an increase in the mass spectrum of hydrogen isotope peaks with higher numbers (complexes), associated with the passage of the hydrogen isotopes through a membrane heated by thermal radiation or by the glow discharge plasma (Fig. 9), as compared with a control spectrum taken from gas obtained

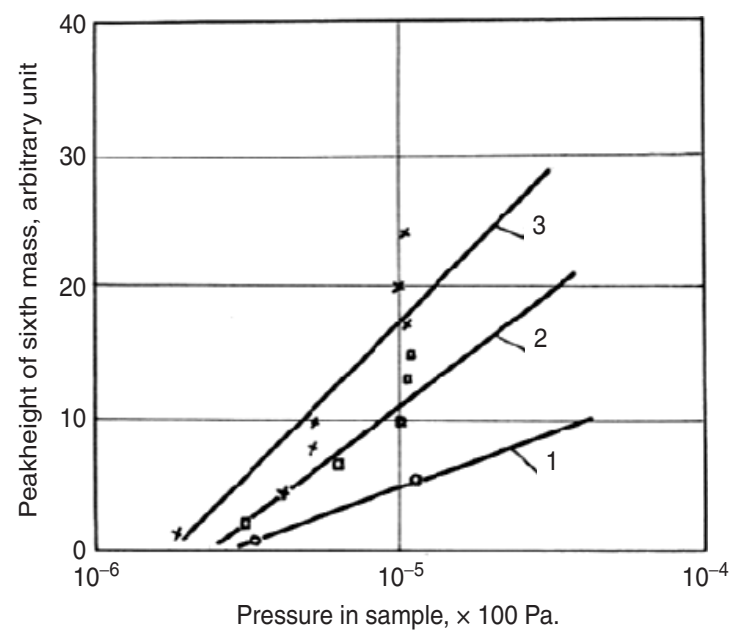

Figure 9. Mass 6 versus pressure. 1: Deuterium flow through valve leak; 2: deuterium flow through niobium, resistive heating; 3: deuterium flow through niobium, discharge. 


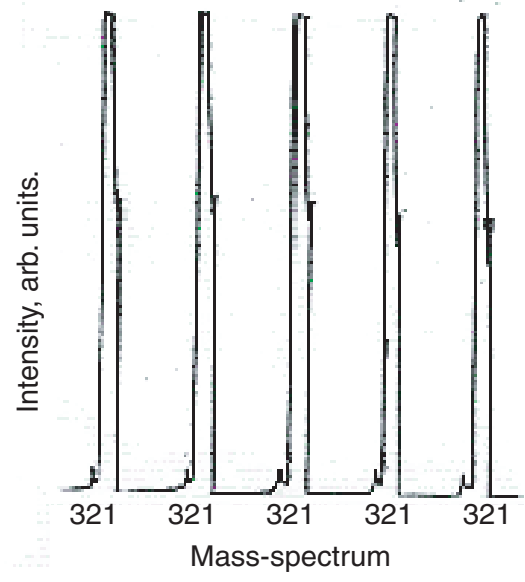

(a)

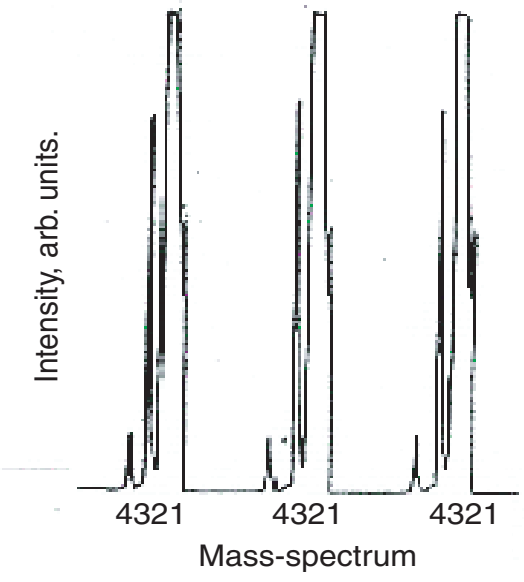

(b)

Figure 10. The mass-spectrum of protium mass for the membrane of vanadium. (a) at $300 \mathrm{~K}$; (b) in the glow discharge $\left(V=200 \mathrm{~V}, J=50 \AA / \mathrm{m}^{2}, T=900 \mathrm{~K}\right)$.

through a leak valve. The fixed complexes are stable enough, since they pass through about one meter of gas before detection in the mass spectrometer. These complexes can testify to the occurrence in these experiments of new elements, such as deuterium or tritium. The appearance of these long-lived complexes may be associated with the occurrence of excess heat.

In Figs. 10(b) and 11(b) the mass-spectra of a natural mix of hydrogen, and of

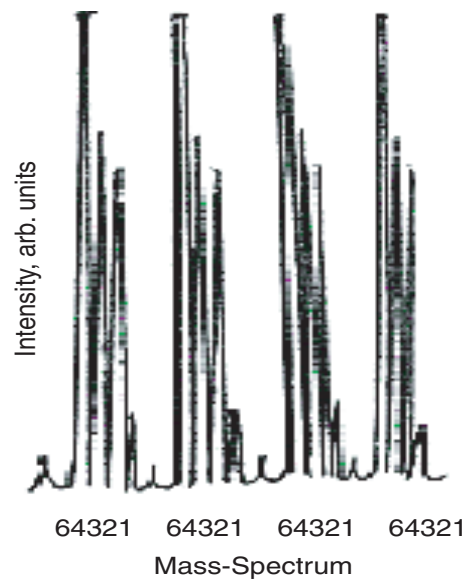

(a)

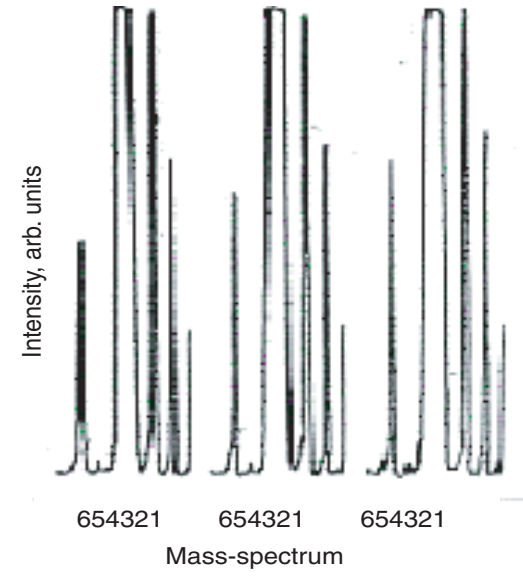

(b)

Figure 11. The mass-spectrum of deuterium mass for the membrane of vanadium. (a) at $300 \mathrm{~K}$; (b) in the glow discharge $\left(V=200 \mathrm{~V}, J=50 \AA / \mathrm{m}^{2}, T=1000 \mathrm{~K}\right)$. 


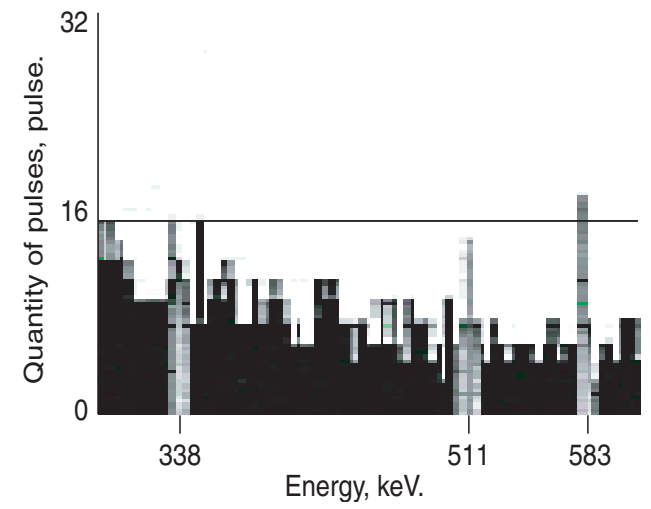

Figure 12. Background gamma spectrum from the installation with the discharge off. The exposure time is $7000 \mathrm{~s}$.

deuterium, after passage through the membrane of vanadium is shown, following irradiation by accelerated ions from the glow discharge plasma. It cam be seem that from a comparison with the initial spectra (Figs. 10(a) and 11(a)) there occurs in both cases an increase in heavy complexes; masses 3,4 in the case of hydrogen, and masses 5,6 in the case of deuterium. In the case of hydrogen, the mass 3 peak is stronger than the mass 4 peak. In the case of deuterium, the mass 6 peak is stronger than the mass 5 peak. This seems reasonable when thought of in terms of three-atom complexes: the mass 3 peak of $\mathrm{H}-\mathrm{H}-\mathrm{H}$ should be stronger than the mass 4 peak of $\mathrm{H}-\mathrm{H}-\mathrm{D}$ in the hydrogen discharge; and the mass 6 peak of $\mathrm{D}-\mathrm{D}-\mathrm{D}$ should be stronger than the mass 5 peak of $\mathrm{D}-\mathrm{D}-\mathrm{H}$ in the deuterium discharge.

The height of the peak with mass 3 for hydrogen reached $50 \%$ of the peak with mass 2 ; and the height of the peak with mass 6 for deuterium reached $20 \%$ of the from peak with mass 4; following passage of the hydrogen isotopes through a niobium membrane in glow discharge experiments. It was possible only to find trances of mass 5 and mass 6 in the case of vanadium and niobium in a hydrogen discharge. It was not possible to observe heavier complexes with mass 7-9 in the case of vanadium and niobium in a deuterium discharge. It seems clear that the peaks of mass 3-4 for hydrogen, and mass $5-6$ for deuterium, are connected to deuterium generation in these the glow discharge experiments. Although tritium generation occurs as reported above, it was not possible to detect tritium through the use of mass spectrometers due to the low resolution.

\subsection{Radiation measurements}

We present in Table 6 results of gamma radiation measurements; where the foreground measurements were taken during discharge operation, and the background measurements were taken with the discharge off. Values for number of counts (pulses) in the peak areas, along with energies and identification of isotopes that are candidates for lines at the gamma energy. In the background spectra of the 


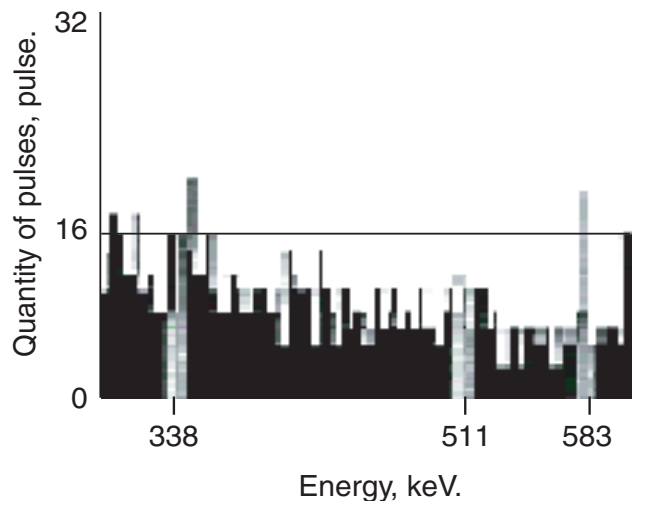

Figure 13. Foreground gamma spectrum taken with the discharge on. The exposure time was also $7000 \mathrm{~s}$.

facility, and in the discharge spectra, there are gamma peaks for U-235, Th-232, and their disintegration products (Tl-208 and Pb-212); and also K-40 and Cs-137. The background gamma spectrum in a range $330-590 \mathrm{keV}$ is shown in Figure 12; and the foreground spectrum taken with the discharge on is shown in Figure 13.

The number of counts measured over $700 \mathrm{~s}$ at $511 \pm 1 \mathrm{keV}$ with the discharge on is 45 , and with the discharge off is 74 . This difference corresponds a standard deviation for this measurement. The number of counts at this energy is so small

Table 6. The values of pulses quantity for the allocated zones of a $\gamma$-spectrum at working installation, without inclusion of the glow discharge (background) and at interaction of a natural mix of hydrogen isotopes with niobium at influence of the glow discharge and imposing of the magnetic field $(I=3,1 \AA$; $V=450 \mathrm{~V}$; $T=1020 \mathrm{~K})$

\begin{tabular}{ccccc}
\hline $\begin{array}{c}\text { zone } \\
\text { index }\end{array}$ & $\begin{array}{c}E_{\gamma} \\
\mathrm{KeV}\end{array}$ & $\begin{array}{c}\text { peak area } \\
\text { (background) }\end{array}$ & $\begin{array}{c}\text { peak area } \\
\text { (with discharge) }\end{array}$ & isotope (parent) \\
\hline 1 & $90 \pm 0.5$ & 0 & 15 & $\mathrm{U}-235$ \\
2 & $143.8 \pm 0.5$ & 5 & 8 & $\mathrm{U}-235$ \\
3 & $163.4 \pm 0.5$ & 0 & 0 & $\mathrm{U}-235$ \\
4 & $185.7 \pm 0.5$ & 10 & 4 & $\mathrm{U}-235$ \\
5 & $205.3 \pm 0.5$ & 0 & 1 & $\mathrm{U}-235$ \\
6 & $221.4 \pm 0.5$ & 0 & 0 & $\mathrm{U}-235$ \\
7 & $238.6 \pm 0.7$ & 45 & 40 & $\mathrm{~Pb}-212(\mathrm{Th}-232)$ \\
8 & $338.3 \pm 0.7$ & 4 & 14 & Ac-228 (Th-232) \\
9 & $511 \pm 1$ & 74 & 45 & Tl-208 (Th-232) \\
10 & $583 \pm 1$ & 28 & 7 & Tl-208 (Th-232) \\
11 & $661.7 \pm 1$ & 31 & 18 & Cs-137 \\
12 & $727 \pm 1$ & 9 & 0 & Tl-208 (Th-232) \\
13 & $763 \pm 1$ & 4 & 0 & Tl-208 (Th-232) \\
14 & $911 \pm 1.5$ & 26 & 5 & Ac-228 (Th-232) \\
15 & $1001 \pm 1.5$ & 0 & 0 & Pa-234m (U-238) \\
16 & $1173.2 \pm 1.5$ & 2 & 0 & Co-60 \\
17 & $1460 \pm 1.5$ & 35 & 27 & K-40 \\
18 & $1588 \pm 1.5$ & 5 & 20 & Ac-228 (Th-232) \\
\hline
\end{tabular}

The peak area is in units of counts. 
that the associated error is $\pm 50 \%$. Thus it is possible to conclude that positron generation does not occur in association with the glow discharge at a detectable level, and that the $511 \mathrm{KeV}$ signal is due to the natural disintegration of Tl-208, with is a product of Th-232 decay.

\section{Discussion}

\subsection{Tritium generation using the new technique}

With the new experimental technique presented here, in which care is taken to prevent spurious tritium signals from the equipment and working chamber, we have evidently demonstrated that the tritium generation rate can be increased. These results are in the contradiction with tritium evolution due to thermal activation, where the apparent tritium generation rate increase exponentially with temperature. $^{5}$ Therefore, it is possible to consider these results as contributing to the proof that the tritium generation observed in the glow discharge discharge experiments has a nuclear origin. It is especially important that significant tritium generation rate is observed using a natural mix of hydrogen isotopes in the (plasmaforming) gas. The tritium generation rate depends very strongly on the geometry of the discharge. The reasons for the advantage of the planar glow discharge scheme for tritium generation are at present not clear.

The low results obtained with helium are essential to an understanding of the nature of tritium generation. These results can provide estimates for the influence of radiating size, thermo-desorption effects, and electro-migration effects, on the tritium generation rate in similar experiments. These experiments can be carried out conveniently with other inert gases, in particular, with argon.

The significant influence of the magnetic field in the interaction area (for hydrogen isotopes with the metal surface metals) on the tritium generation rate supports the the notion that tritium generation is due to (nuclear reactions), and not due to thermal activation. The magnetic field can impact the tritium generation rate indirectly through a modification of the glow discharge discharge parameters, and directly through the character of the interaction of the isotopes with the metal surface. In the latter case, the magnetic field can influence the orientation of atoms, nuclei, and electrons required for tritium generation.

The new approach has shown an opportunity to achieve very significant tritium generation rates, even when a natural mixture of hydrogen isotopes is used. The demonstrated rate of tritium production in the range $10^{9}-10^{10}$ atom/s allows it to be measured using standard scintillation techniques. The rate for tritium generation production increases with the addition of deuterium, but by an amount less than an order of magnitude even when the deuterium concentration is increased by 4-5 orders of magnitude. It is possible to conclude from this that the dependence of the tritium generation rate on the initial deuterium concentration is not as great as might have been expected. 


\subsection{Excess power using relative measurements}

The technique used for the measurement of the excess power has advantages, despite the impossibility of developing an absolute estimate, has advantages as a relative measurement. The relative measurement can be done with rather high accuracy $( \pm 20 \%)$ and good sensitivity $( \pm 0.1 \mathrm{~W})$. The primary appeal of this new technique, which we have developed and reported, is that excess power is considered to be demonstrated when the temperature increases only when the sample is filled (relative to the case where it is evacuated), all other experimental parameters being equal.

The excess thermal power generation is rather complex a high-temperature process; which depends on the interaction of accelerated ions of hydrogen isotopes with metals in the glow discharge plasma, and with surface processes (such as sorption, desorption, and solubility). The maximal relative efficiency of the excess power generation is observed in a range of temperatures $600-700 \mathrm{~K}$; and and the absolute efficiency is maximized in the range $800-1000 \mathrm{~K}$.

The excess heat generation on the sample operating as an anode is approximately half than when operating as a cathode; hence it is possible to assume that the basic activation means for the process is a thermal activation. The presence of an optimum on pressure of hydrogen isotopes in the range $0.04-0.1 \mathrm{MPa}$ (and also unexpectedly a dependece on the flow), does not yet have a simple explanation. It is probably associated with the complex kinetics of formation of double and threefold complexes reported in $[1,13]$ and tritium generation. ${ }^{3,15}$

Small differences in the excess heat measured for deuterium, and for anatural mix of a hydrogen isotopes, shows that in the new approach for excess heat generation the usual nuclear processes do not play an essential role.

\subsection{Tritium generation characteristics}

The experimental scheme with the cylindrical cathode sample is not optimum for maintaining an acceptable tritium generation rate. ${ }^{4,14}$ It allows us to obtain a tritium generation rate not above $10^{9}$ atom/s; which corresponds to estimates of a maximum quantity of heat at the expense of nuclear reactions arising in low-energy interaction of hydrogen isotopes with metals at a level on the order of watts, ${ }^{10,13}$ as we will discuss later on. The excess power values measured in the present work are in the range $0.5-4.5 \mathrm{~W}$.

There is evidence for an increase in deuterium concentration, based on the increase in the mass 3-4 peaks in the mass spectra for a hydrogen discharge, and an increase in the mass 5-6 peaks in the case of a deuterium discharge. The absence of mass 7-9 peaks is due to the fact that tritium generation is much slower, and sensitivity of mass-spectrometers is not sufficient for measuring such low levels of tritium. The implication is that the tritium generation occurs as a secondary $\mathrm{p}+\mathrm{d}$ nuclear reaction, and high energy deuterons may be generated from $\mathrm{p}+\mathrm{p}$ nuclear reactions, as confirmed by the measurements of the increase of 3-6 mass in the mass spectrometer data. 
With regard to the character of the reactions involved in tritium generation (during the interaction of hydrogen isotopes with a metal surface during the glow discharge), the results indicate the following features which have been found in similar experiments:

(1) Tritium generation does not depend directly on temperature.

(2) Tritium generation depends basically on the experimental parameters that relate to the of force of interaction of the hydrogen isotopes (current, voltage, characteristics of the magnetic field). With an increase of the voltage and current, the tritium generation rate grows.

(3) The tritium generation rate has an obvious dependence on the nuclear number (mass number) of the bombarded material by ions of hydrogen isotopes from the glow discharge plasma. The best results are obtained in the case of heavy metals, such as tantalum, tungsten, platinum.

(4) The tritium generation rate does not depend directly on the amount of hydrogen dissolved in metal.

(5) With the transport by diffusion of the hydrogen isotopes through the metal wall under discharge conditions, tritium collects behind a membrane, instead of before it. This is contrary to the isotope diffusion effect.

(6) Electromigration is also insignificant in affecting the tritium output from the cathode sample, since in the metals that we used hydrogen is partially ionized with a positive charge.

\subsection{Reaction mechanisms proposed}

It is possible to judge the form of the reactions responsible from experiments with the detection of gamma radiation near $511 \mathrm{keV}$. The experiments have shown that gamma radiation in this area is not registered. Hence, the specified reactions can go only as threefold, with catalysis by means of electrons; i.e. the basic reaction in similar experiments is:

$$
\mathrm{p}+\mathrm{e}+\mathrm{p} \rightarrow \mathrm{d}(\sim 2 \mathrm{keV})+\nu(\sim 1.95 \mathrm{MeV})
$$

[Such reactions assume electrons influence of the solid on stability of hydrogen molecules and specificity for products of reaction.] This reaction is remarkable in that any radioactive byproducts are absent. Most of the reaction energy is carried away by the neutrino, soft X-ray radiation is observable, and high-energy radiation is absent. The energy associated with tritium generation is three orders of magnitude less that that associated with the energy observed due to the majority of thermonuclear reactions. The same reaction can serve a source of energetic deuterons for similar reactions based on $\mathrm{p}+\mathrm{e}+\mathrm{d}$. Hence tritium generation under the conditions specified can occur in pure hydrogen, without deuterium as an impurity. The rate of secondary nuclear reactions is smaller on average in the range $10^{-5}-10^{-7}$ (with an average of $10^{-6}$ ). 
Since the maximum tritium generation rate was observed for mixtures of hydrogen and deuterium, we believe that the tritium was formed not from thermonuclear D-D reactions, but instead from

$$
\mathrm{p}+\mathrm{e}+\mathrm{d} \rightarrow \mathrm{T}(\sim 6 \mathrm{keV})+\nu(\sim 5.98 \mathrm{MeV}) .
$$

Such reaction can proceed due to impurity deuterium in hydrogen and through secondary deuterons formed from $\mathrm{p}+\mathrm{e}+\mathrm{p}$ reactions. The measured power for this reaction is also three orders of magnitude lower than the power from the majority of thermonuclear reactions. A similar reaction can result in the formation of ${ }^{4} \mathrm{He}$ :

$$
\begin{aligned}
& \mathrm{p}+\mathrm{e}+\mathrm{T} \rightarrow 4 \mathrm{H}(\sim 15 \mathrm{keV})+\nu(\sim 19.8 \mathrm{MeV}) \\
& \downarrow \\
& 4 \mathrm{He}(\sim 15 \mathrm{eV})+\beta^{-}(\sim 15 \mathrm{keV}) .
\end{aligned}
$$

The reactions proposed correspond best in our opinion to observable products in the majority of experiments on the low-energy interaction of the hydrogen isotopes with metals in measurements of deuterium, tritium, helium-4, excess heat and X-ray radiation with the certain energy.

\subsection{Reaction strength}

It is known that the coupling constant for weak interactions of particles is approximately five orders of magnitude less than for the strong force, and cross sections for weak interactions are approximately 14 orders of magnitude less than for the strong force. However, the corresponding interaction time for weak interactions has a large duration (more than $10^{-8} \mathrm{~s}$ ), which can affect the character of the interaction. Weak reactions can go spontaneously at low energy (beta-disintegration).

If the instability of hydrogen atoms or molecules (interacting with electrons in the energetic field of metals) will be proved, the significant reduction of the influence of the Coulomb barrier on the proposed reactions can compensate to increase the reaction cross section associated with weak interactions. Hence if the cross section of the proposed reactions occur at a level $10^{-40}-10^{-30} \mathrm{~cm}^{2}$ (instead of $10^{-25} \mathrm{~cm}^{2}$, as is the case for the strong force) even this cross section can appear sufficient for practical applications, even though it is connected to substantial growth of an active zone. That weak interactions can occur only on a much smaller distance scale, in comparison with the strong force $\left(10^{-18} \mathrm{~m}\right.$ in comparison with $\left.10^{-15}-10^{-16} \mathrm{~m}\right)$ is in this case not the determining factor. The conventional thermonuclear reactions of

$$
\mathrm{p}+\mathrm{e}+\mathrm{p} \rightarrow \mathrm{d}+\beta^{+}+\nu+0.42 \mathrm{MeV}
$$

and

$$
\mathrm{p}+\mathrm{d} \rightarrow{ }^{3} \mathrm{He}+\gamma+5.494 \mathrm{MeV}
$$


have low interaction cross sections, even at energies of several MeV. These thermonuclear reactions go with a small speed, even at small distances between nucleons. Therefore, when the complex $\mathrm{p}+\mathrm{d}+\mathrm{d}$ (having received energy in plasma of the glow discharge and having collided with a metal target, which in this case plays a anvil role) begins collapsing a thermonuclear reaction probably goes, but we can not observe it because of the low interaction cross section. Further that distance $p+d$ theoretically can be as much as small and possible to decrease of the Coulomb barrier in a complex $\mathrm{p}+\mathrm{d}+\mathrm{p}$ or $\mathrm{p}+\mathrm{d}+\mathrm{d}$, practically, up to zero. Even energies of some hundreds of electron volts appears to be sufficient for collisions of the specified complexes down to distances on the order of $10^{-18} \mathrm{~m}$ due to shielding. There is enough to time for the course of such processes a stationary glow discharge plasma ( 10 ms).

\subsection{Resulting estimates and potential appliciations}

The results presented show that if we assume the novel $\mathrm{p}+\mathrm{e}+\mathrm{d}$ reactions $^{13}$ discussed above, and take the observed tritium generation rate of $10^{10}$ atom/s, then the resulting thermal power is about $10^{-5} \mathrm{~W}$. If we proceed from the assumption that tritium generation is a consequence of much more intense $\mathrm{p}+\mathrm{e}+\mathrm{p}$ reactions with $(\mathrm{KeV})$ deuterium formation (where tritium results approximately one in $10^{6}$ of time) the tritium generation rate measured implies a thermal generation from the new $\mathrm{p}+\mathrm{e}+\mathrm{p}$ reactions discussed above at a power level of about $10 \mathrm{~W}$. These estimates correspond to our experiments on excess heat production. ${ }^{3,16}$ For the development of thermal energy due to nuclear reactions at a level comparable with the input electrical energy (some $\mathrm{kW}$ ), the tritium generation rate should would need to be about $10^{12}$ atom/s.

There has been at least one hundred models and theories proposed, but none of them can give an unequivocal explanation for the experimental data. Nevertheless, such features of the new proposed reactions have an overwhelming advantage with the participation only of protons, and since the only radioactive product present is tritium in small amounts. This allows us to plan the basic directions of practical use of nuclear reactions arising from the low-energy interaction of hydrogen isotopes with metals:

- Power

- Wastes storage and processing

(A) Wastes processing with tritium.

(B) Processing of high active, heavy wastes.

- Production of rare isotopes.

- Development of new materials.

- Isotope light sources and energy.

- Generators of coherent radiation (Lasers). 


\section{Conclusions}

(1) The introduction of a magnetic field perpendicular to the sample surface (in the interaction of hydrogen isotopes with metals in the glow discharge plasma) has resulted in an increase in the observed tritium activity, and in the tritium generation rate, by almost two orders of magnitude, as compared with the same experiments with no magnetic field.

(2) Tritium generation rates as high as $10^{9}-10^{10}$ atom/s have been observed in glow discharge experiments with mixtures of hydrogen isotopes in a glow discharge operating in a magnetic field, exceeding the test background level by three to four orders of magnitude. The use of a magnetic field has ensured good reproducibility for these results, and the reliable achievement of a tritium generation rate near $10^{10} \mathrm{atom} / \mathrm{s}$ in the case of tantalum, tungsten, and platinum.

(3) A new technique for excess heat generation and detection has been proposed, in which the transfusion of hydrogen isotopes occurs through the metal wall of a hollow tight sample (in the direction to the glow discharge) where the sample constitutes one of the discharge electrodes. For samples of vanadium, the maximum excess thermal power is about about $30 \%$ of the power absorbed by the sample (when operating as a cathode). Excess power generation is optimized at temperatures in the range 600-700 (for relative power) and $800-1000 \mathrm{~K}$ (for the absolute power).

(4) In the spectra taken with a mass spectrometer, the appearance of mass 3 and 4 peaks in the case of a hydrogen discharge, and the appearance of mass 5 and mass 6 peaks in the case of a deuterium discharge (as compared to spectra taken under thermal activation), supports the conjecture that deuterium is generated in the experiments.

(5) The gamma spectrum of the working installation with the discharge included, and without, differed a little. The difference between the two measurements did not exceed the estimated experimental error of $\pm 50 \%$. Thus it is possible to assert that there is no significant generation of positrons during glow discharge operation.

(6) Features of the experiments discussed in this work are consistent with a nuclear origin of tritium generation (arising from the interaction of the glow discharge plasma with a metal surface), and not consistent with conventional tritium evolution through thermal activation.

(7) The established increase of the amount of deuterium which is observable (associated with the interaction of hydrogen isotopes with metals in the glow discharge plasma) for mixes of isotopes (both in the case of hydrogen gas, and deuterium gas) from mass spectroscopic measurements; and the incommensurate increase in the tritium generation rate as a function of deuterium concentration; and absence of positrons; together, allow us to assert that the nuclear reactions $\mathrm{p}+\mathrm{p}$ and $\mathrm{p}+\mathrm{d}$ (with the corresponding formation of deuterium and tritium) proceed through electronic catalysis as $\mathrm{p}+\mathrm{e}+\mathrm{p}$ and $\mathrm{p}+\mathrm{e}+\mathrm{d}$.

(8) It is a stated assumption that for the generation of thermal energy at a level of about $1 \mathrm{~kW}$, an associated tritium generation rate of about $10^{12}$ atom/s would occur, based on the low energy nuclear reactions under discussion in this work. 


\section{References}

1. V.A. Romodanov, V.I. Savin, M.V. Shakhurin et al., Zhurnal Tekhnicheskoy Fiziki, 61(5), 122-125 (1991) (in Russian).

2. V.A. Romodanov, V.I. Savin, Ya.B. Skuratnik and Yu.M. Timofeev, Reaction of Nuclear Fusion in Condensed Matter - Voprosy Atomnoj Nauki i Tekhniki. Ser: Radiation Damage Physics and Radiation Technology, 1992, 1(58), 2(59), 73-82. (In Russian).

3. V.A. Romodanov, V. Savin, Ya. Skuratnik and Yu. Timofeev, in Proceedings of the ICCF-3, Nagoya, Japan, ed. H Ikegami (Universal Academy Press Inc., Tokyo, Japan, 1993), pp. 307-319.

4. V.A. Romodanov, V.I. Savin, Ya.B. Skuratnik, in Proceedings of the ICCF-6, Japan, Vol. 2, ed. M Okamoto (Published by NEDO, IAE. Tokyo, Japan, 1996), pp. 585-589.

5. A. Vitaliy Romodanov, I. Valeriy Savin, B. Yakov Skuratnik and N. Valeriy Majorov, in Proceedings of the ICCF-7, Vancouver, British Columbia, Canada, ed. G Miley (Published by ENECO, Inc., Salt Lake Sity, Utah, USA, 1998), pp. 319-324.

6. V.A. Romodanov, Ya.B. Skuratnik and A.K. Pokrovsky, in Proceedings of the ICCF-8, Vol. 70, ed. F Scaramuzzi (Published by IPS, Bologna, Italy, 2000), pp. 265-268.

7. V.A. Romodanov and Y.B. Skuratnik, Tritium Registration in Metal-Hydrogen Systems - Cold Nuclear Fusion (Materials of the 9-d Russian conference on cold fusion and nuclei transmutation. Sochi, Russian, 30.09-07.10.2001y) M.: SRC PTP "ERZION", 2002, p. 55-62. (In Russian).

8. V. Romodanov, V. Savin, Ya. Skuratnik and V. Elksnin, in Proceedings of the ICCF-4, Lahaina, Maui (Hawaii TR-104188-V3, EPRI, 1994), pp. 1-15.

9. V.A. Romodanov, V.I. Savin, Ya.B. Skuratnik, Yu.N. Zhivluk and A.K. Pokrovskiy, in Proceedings of the ICENES-8'96, Vol. 2, ed. AV Zrodnikov, Russia, IPPE, Obninsk, Kaluga Region, Russia, 1997, pp. 504-511.

10. V.A. Romodanov, Prospects to Intensity Increase of the Nuclear Reactions at LowEnergy Interaction of Hydrogen Isotopes and Possible Areas of their Application Submitted on ICCF-10.

11. V.A. Romodanov, V.I. Savin, Ya.B. Skuratnik and V.N.Majorov, in Proceedings of the ICCF-6, Japan, Vol. 1, ed. M Okamoto (Published by NEDO, IAE, Tokyo, Japan, 1996), pp. 340-346.

12. V. Romodanov, V. Savin, Ya. Skuratnik and S. Korneev, in Proceedings of the ICCF-4, Lahaina, Maui, Hawaii. TR-104188-V3, EPRI, 1994, p. 22(1-13).

13. V.A. Romodanov, The Research of Positrons Annihilation and Possible Ways of $P+D$ Nuclear Reactions - Submitted on ICCF-10.

14. V.A. Romodanov, The Tritium Generation at Low-Energy Interaction of Hydrogen Isotopes with Metals - Submitted on ICCF-10.

15. A. Vitaliy Romodanov, I. Valeriy Savin, B. Yakov Skuratnik, F. Boris Kostenko, S. Vladilen Barashenkov and Z. Michael Yuriev, in Proceedings of the ICCF-7, Vancouver, British Columbia, Canada, ed. G Miley (Published by ENECO, Inc., Salt Lake Sity, Utah, USA, 1998), pp. 325-329.

16. V.A. Romodanov, The Registration of Excess Heat Which Arise at Metal Interaction with Hydrogen Isotopes - Submitted on ICCF-10. 